\title{
Synthetic Route to Enaminones via Metal-Free Four-Component Sequential Reactions of Aryl Olefins with $\mathrm{CHCl}_{3}, \mathrm{Et}_{3} \mathrm{~N}$ and TBHP
}

\author{
Jiantao Zhang ${ }^{\dagger}$, Peng Zhou ${ }^{\dagger}$, Aiguo Yin ${ }^{\star}, *$, Shuhua Zhang ${ }^{\dagger}$, and Weibing Liu ${ }^{\dagger, *}$ \\ ${ }^{\dagger}$ College of Chemistry, Guangdong University of Petrochemical Technology, Guandu Road, \\ Maoming 525000, P. R. China E-mail:lwb409@gdupt.edu.cn; \\ ${ }^{\star}$ College of Biological and Food Engineering, Guangdong University of Petrochemical \\ Technology, Guandu Road, Maoming 525000, P. R. China E-mail: yinlife8@hotmail.com.
}

\section{Contents}

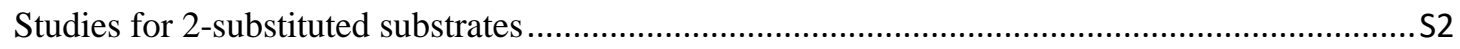

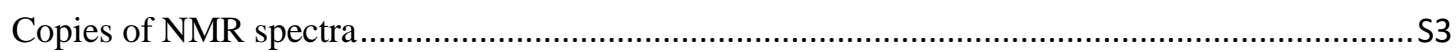




\section{Studies for 2-substituted substrates}

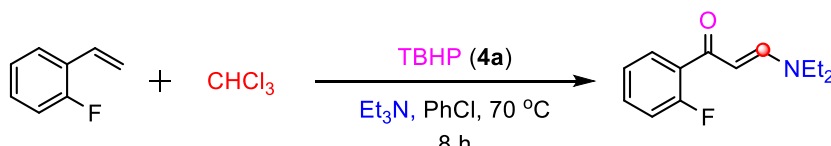

$$
\begin{aligned}
& \text { product } 2-\mathrm{F} \text { : } 10 \%
\end{aligned}
$$

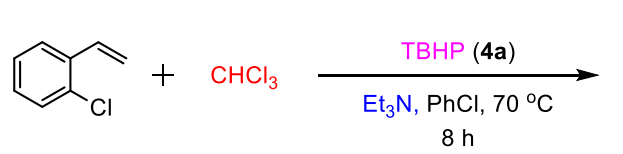<smiles>CCN(C=CC(=O)c1ccccc1Cl)CC</smiles>

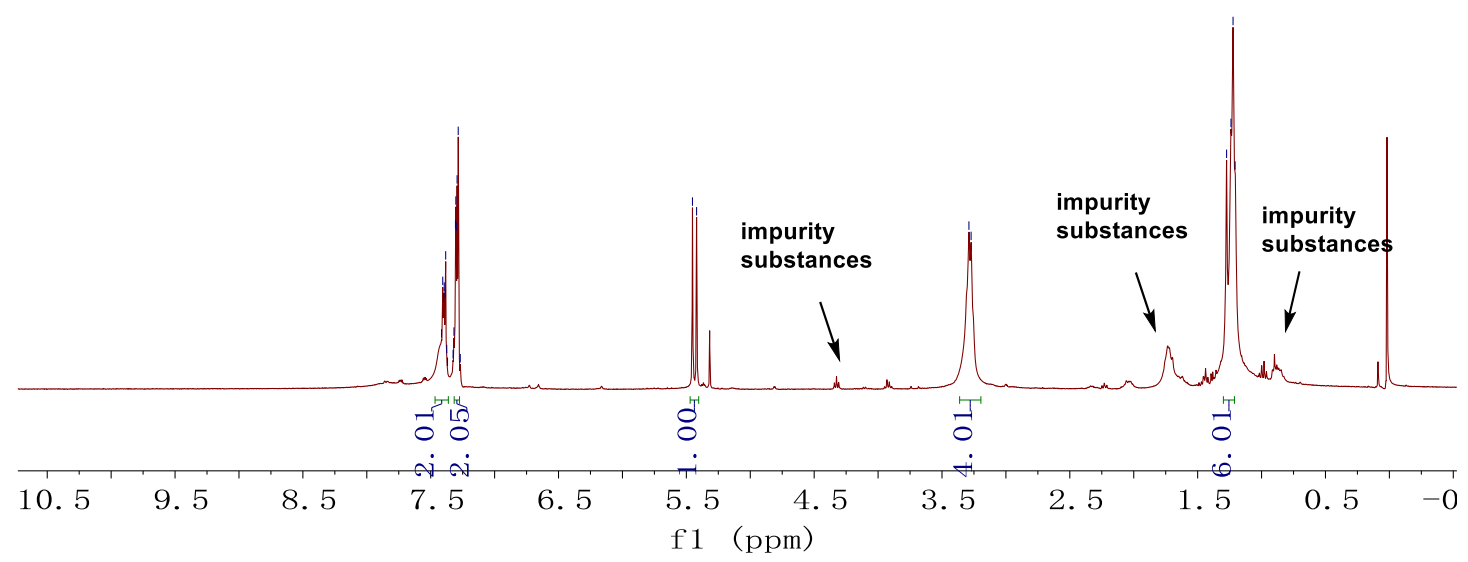




\section{Copies of NMR spectra}

$7 \mathbf{a}$

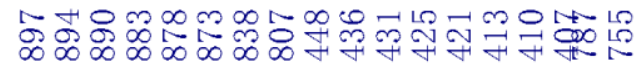

๓ָे

苗觉觉

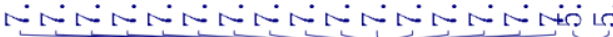<smiles>CCN=CC=C(C)c1ccccc1</smiles>

${ }^{1} \mathrm{H}$ NMR $\left(400 \mathrm{MHz}, \mathrm{CDCl}_{3}\right)$

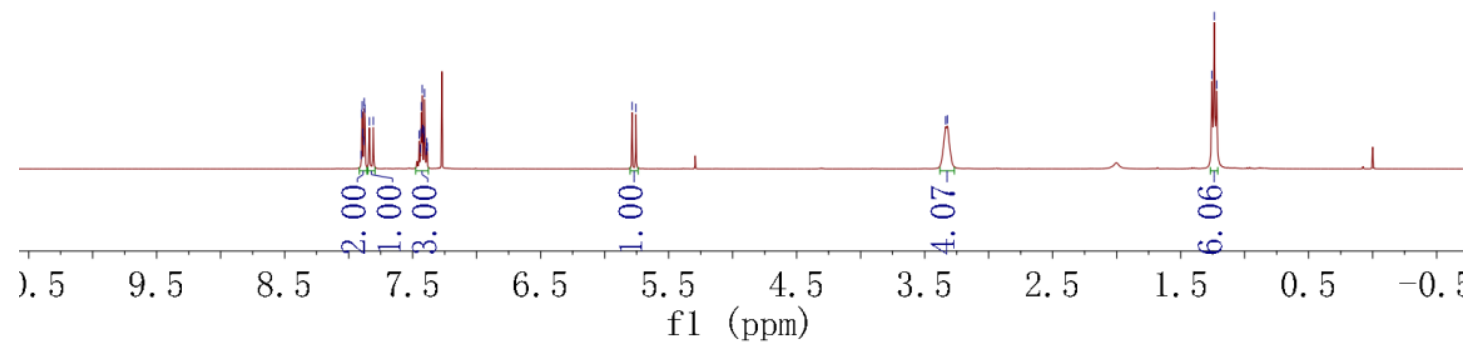

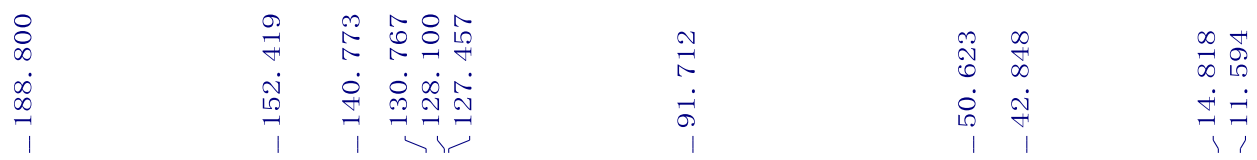<smiles>CCN=CC=Cc1ccccc1</smiles>

${ }^{13} \mathrm{C}\left\{{ }^{1} \mathrm{H}\right\} \mathrm{NMR}\left(101 \mathrm{MHz}, \mathrm{CDCl}_{3}\right)$

\begin{tabular}{|c|c|c|c|c|c|c|c|c|c|}
\hline 200 & 180 & 160 & 140 & 120 & $\begin{array}{l}100 \\
(\mathrm{ppm})\end{array}$ & 80 & 60 & 40 & 20 \\
\hline
\end{tabular}


$7 b$

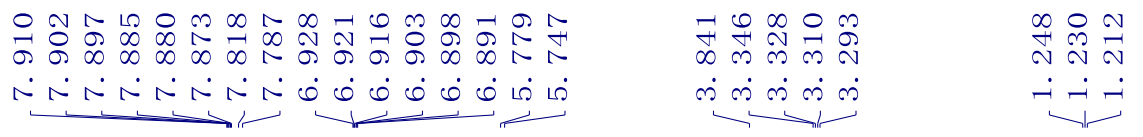<smiles>CCN/C=C/C(=O)c1ccc(OC)cc1</smiles>

${ }^{1} \mathrm{H}$ NMR $\left(400 \mathrm{MHz}, \mathrm{CDCl}_{3}\right)$

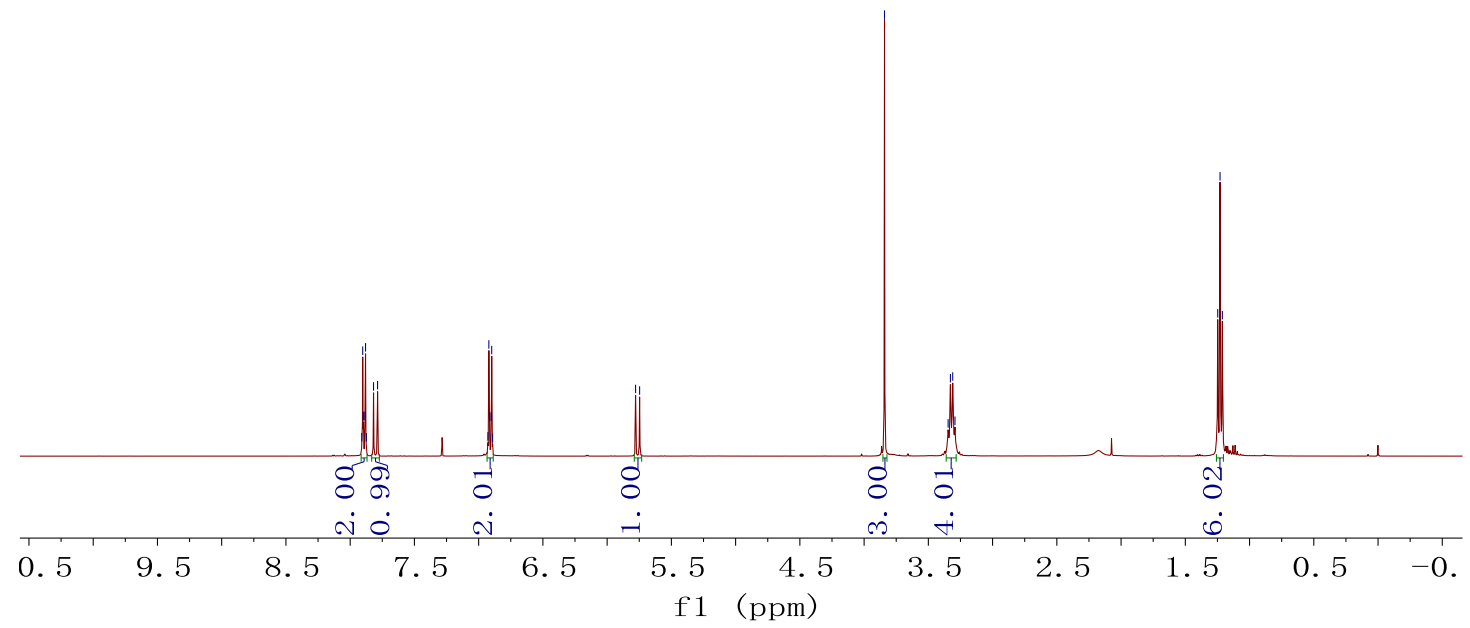

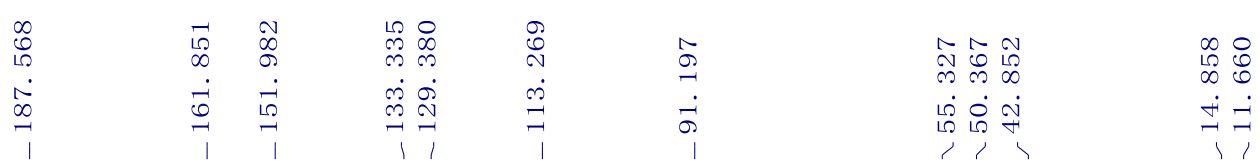

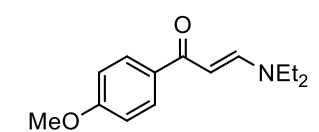

${ }^{13} \mathrm{C}\left\{{ }^{1} \mathrm{H}\right\}$ NMR (101 MHz, $\mathrm{CDCl}_{3}$ )
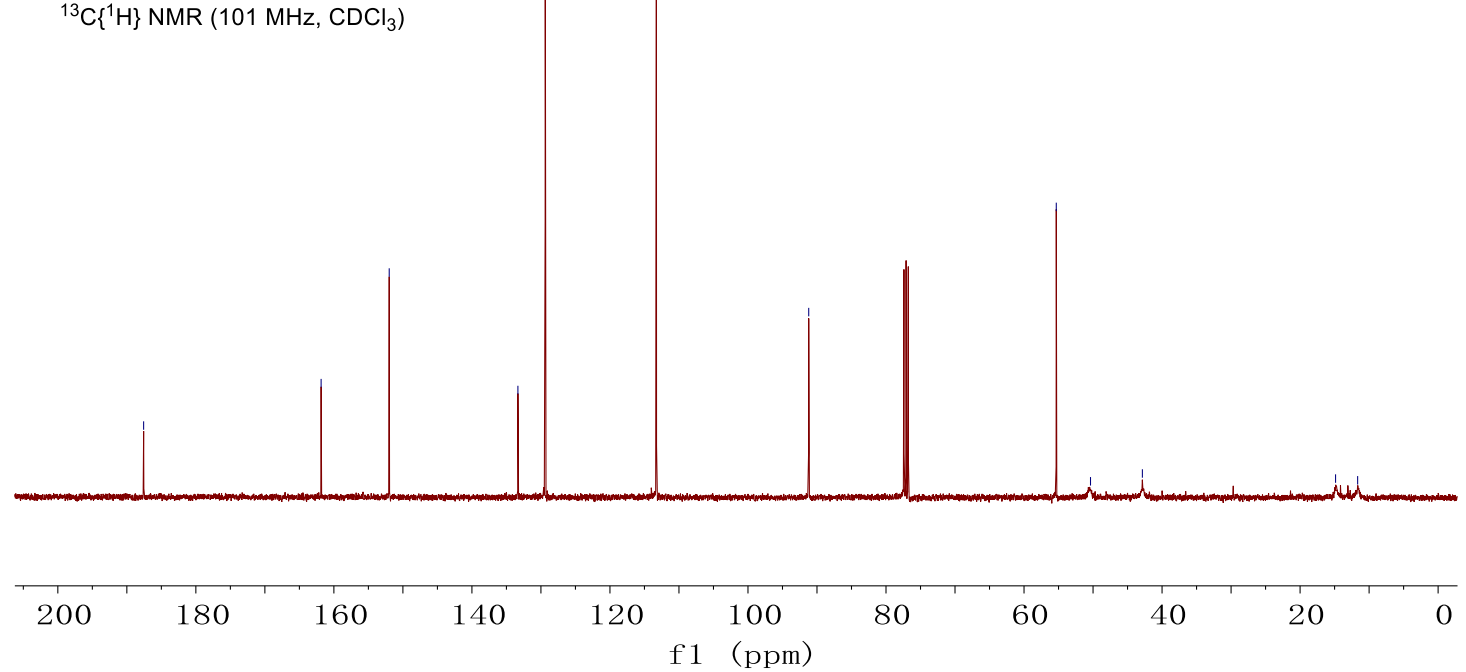
$7 c$

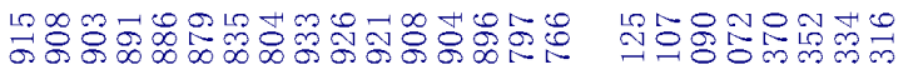

NNNNNN

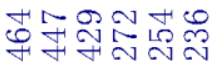

i-i-i-i-i<smiles>CCOc1ccc(C(=O)C=CN(CC)CC)cc1</smiles>

${ }^{1} \mathrm{H}$ NMR $\left(400 \mathrm{MHz}, \mathrm{CDCl}_{3}\right)$

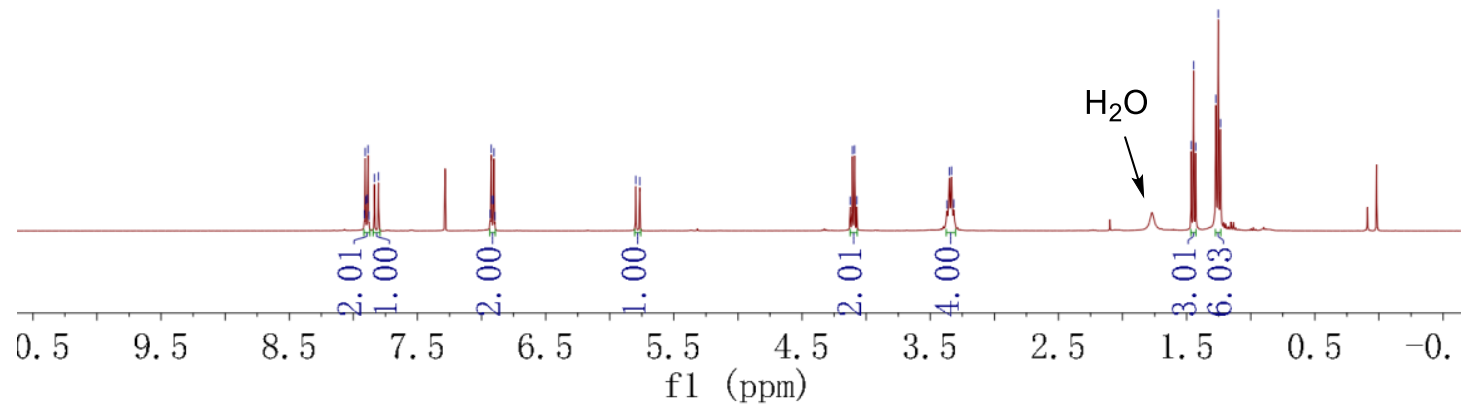

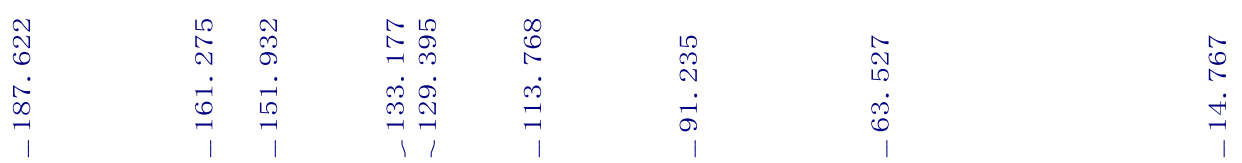<smiles>CCOc1ccc(C(=O)C=CN(CC)CC)cc1</smiles>

${ }^{13} \mathrm{C}\left\{{ }^{1} \mathrm{H}\right\}$ NMR $\left(101 \mathrm{MHz}, \mathrm{CDCl}_{3}\right)$
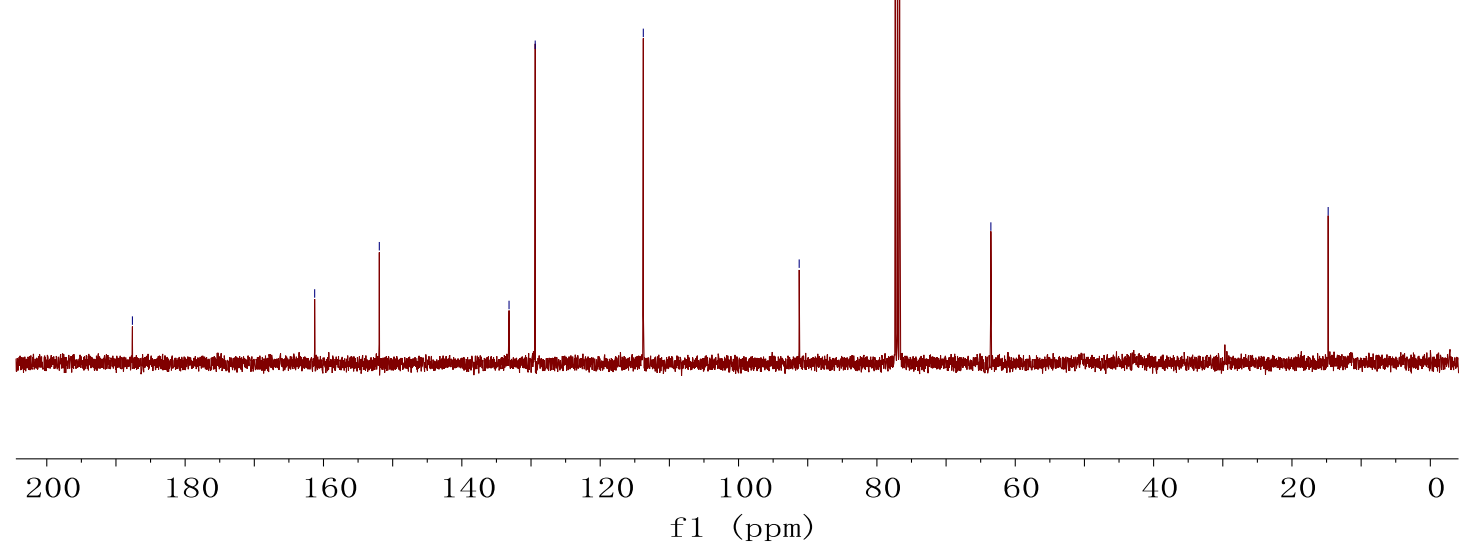
$7 e$

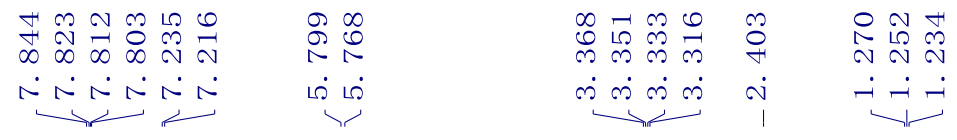<smiles>CCN(/C=C/C(=O)c1ccc(C)cc1)CC</smiles>

${ }^{1} \mathrm{H}$ NMR $\left(400 \mathrm{MHz}, \mathrm{CDCl}_{3}\right)$
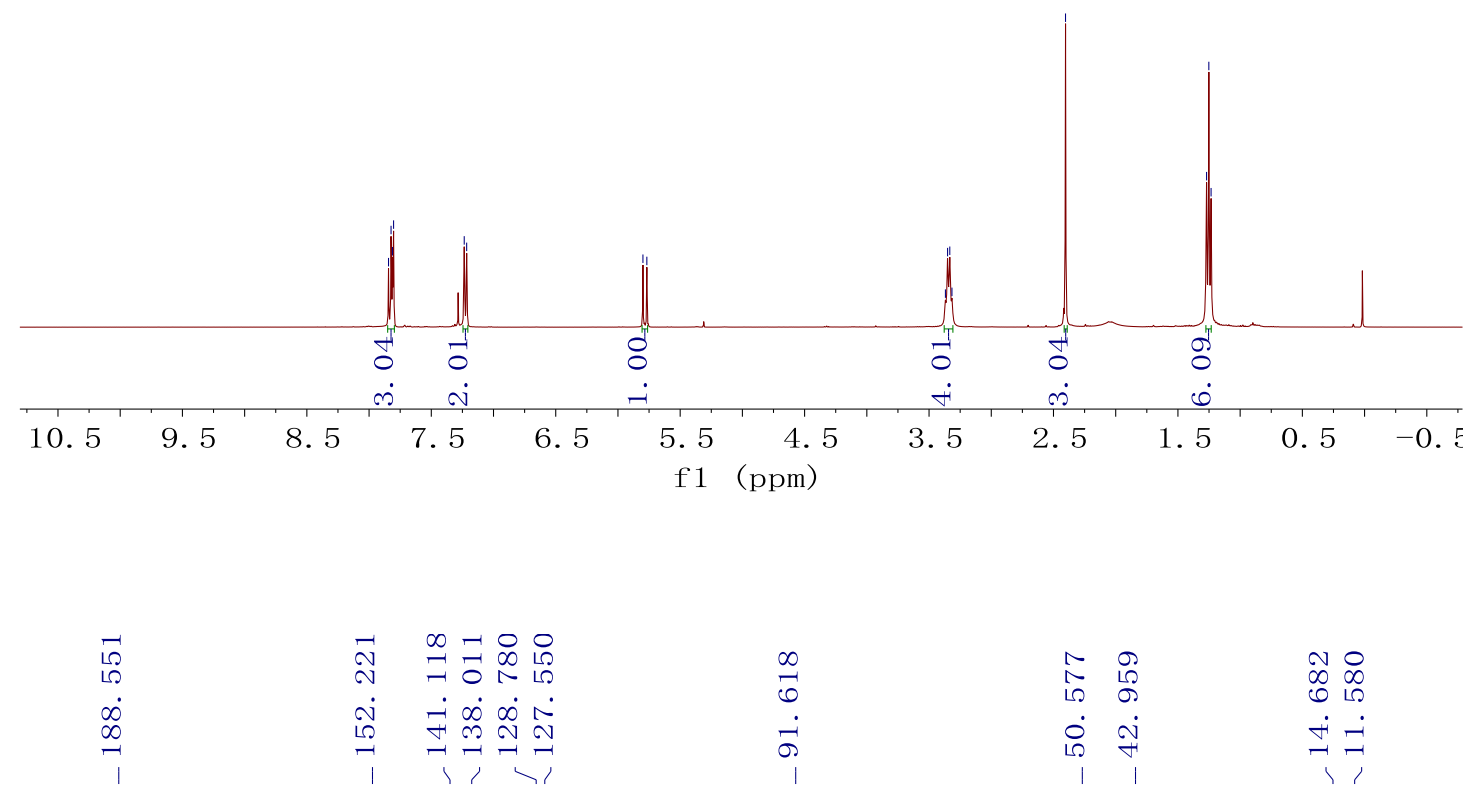

$\begin{array}{ll}1 & \\ \infty & 0 \\ 0 & \infty \\ 0 & 10\end{array}$

$\stackrel{-\dot{\square}}{-}$<smiles>CCN(C=CC(=O)c1ccc(C)cc1)CC</smiles>

${ }^{13} \mathrm{C}\left\{{ }^{1} \mathrm{H}\right\}$ NMR (101 MHz, $\left.\mathrm{CDCl}_{3}\right)$
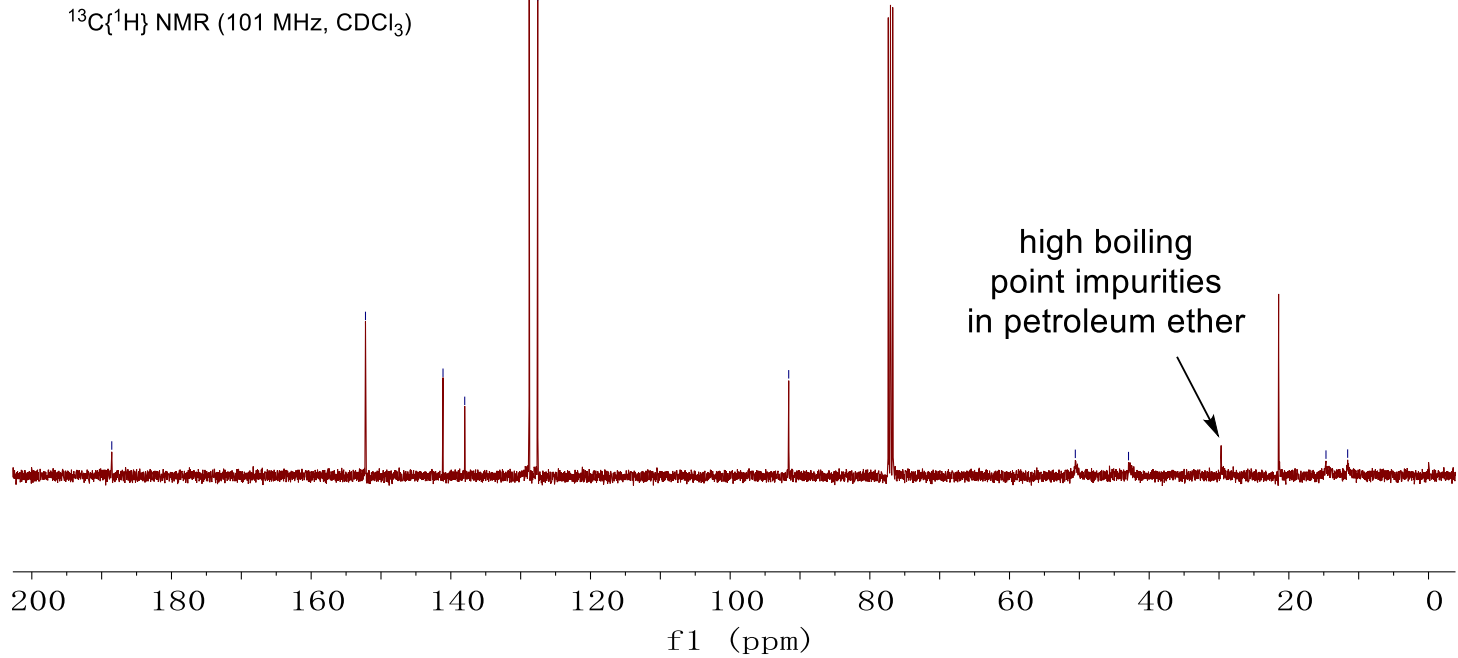
7f

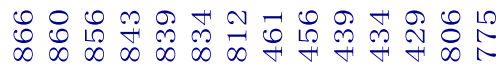

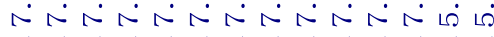

仓ٕ)

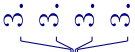

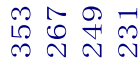

- $-\dot{4}-\dot{2}$<smiles>CCN(C=CC(=O)c1ccc(C(C)(C)C)cc1)CC</smiles>

${ }^{1} \mathrm{H}$ NMR $\left(400 \mathrm{MHz}, \mathrm{CDCl}_{3}\right)$
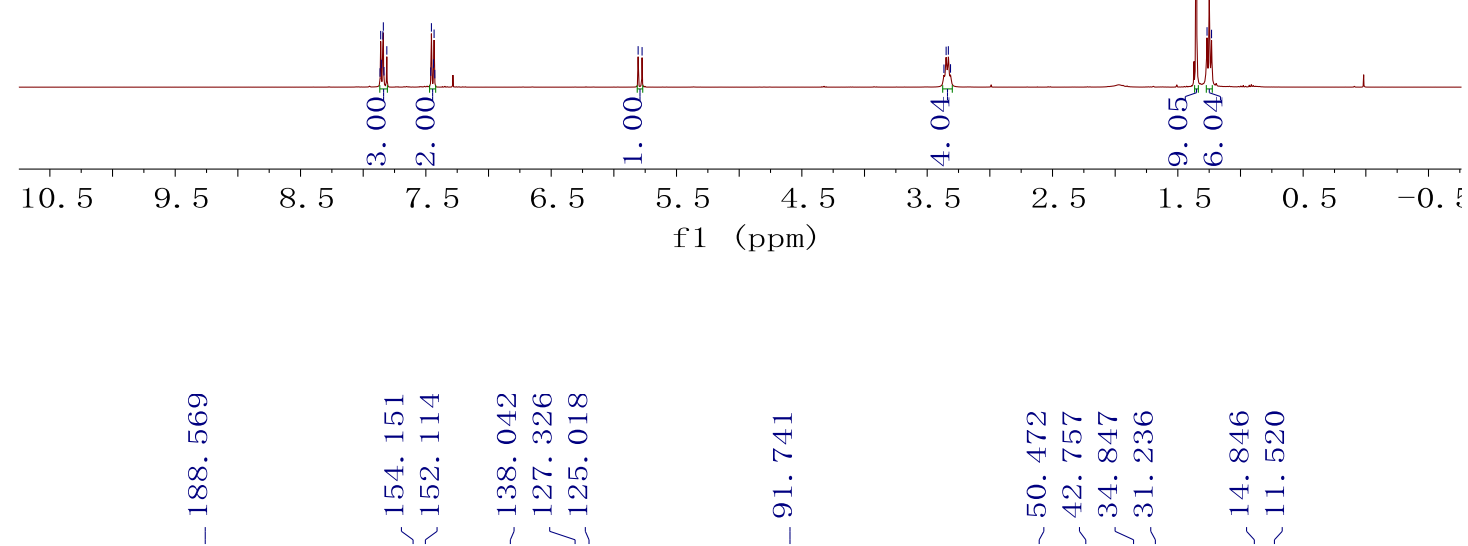

亲

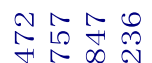

$\stackrel{0}{\circ} \underset{\sim}{\circ}$

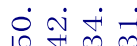

$\stackrel{+}{-}$

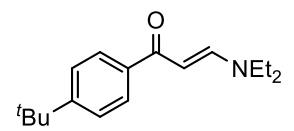

${ }^{13} \mathrm{C}\left\{{ }^{1} \mathrm{H}\right\}$ NMR $\left(101 \mathrm{MHz}, \mathrm{CDCl}_{3}\right)$

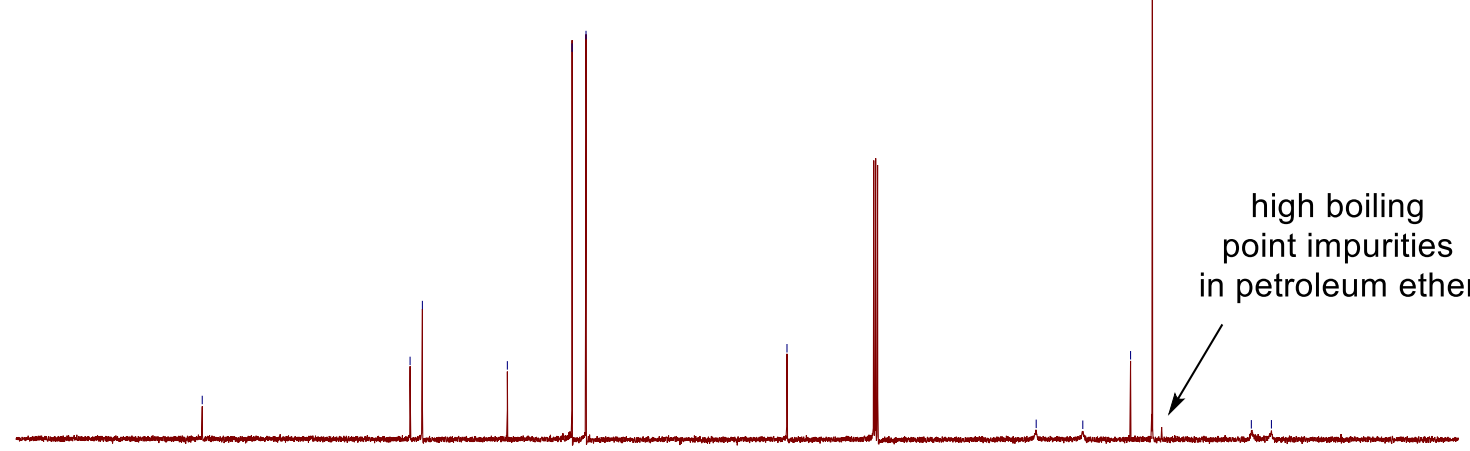

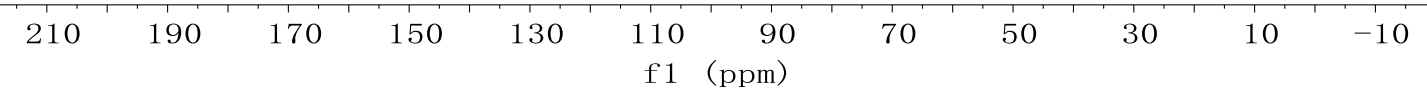




\section{$7 \mathrm{~g}$}

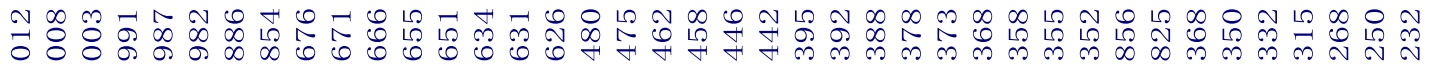

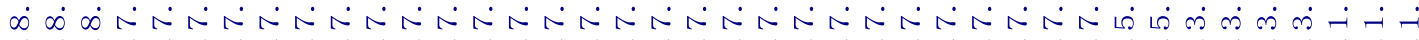<smiles>CCN(C=CC(=O)c1ccc(-c2ccccc2)cc1)CC</smiles>

${ }^{1} \mathrm{H}$ NMR $\left(400 \mathrm{MHz}, \mathrm{CDCl}_{3}\right)$

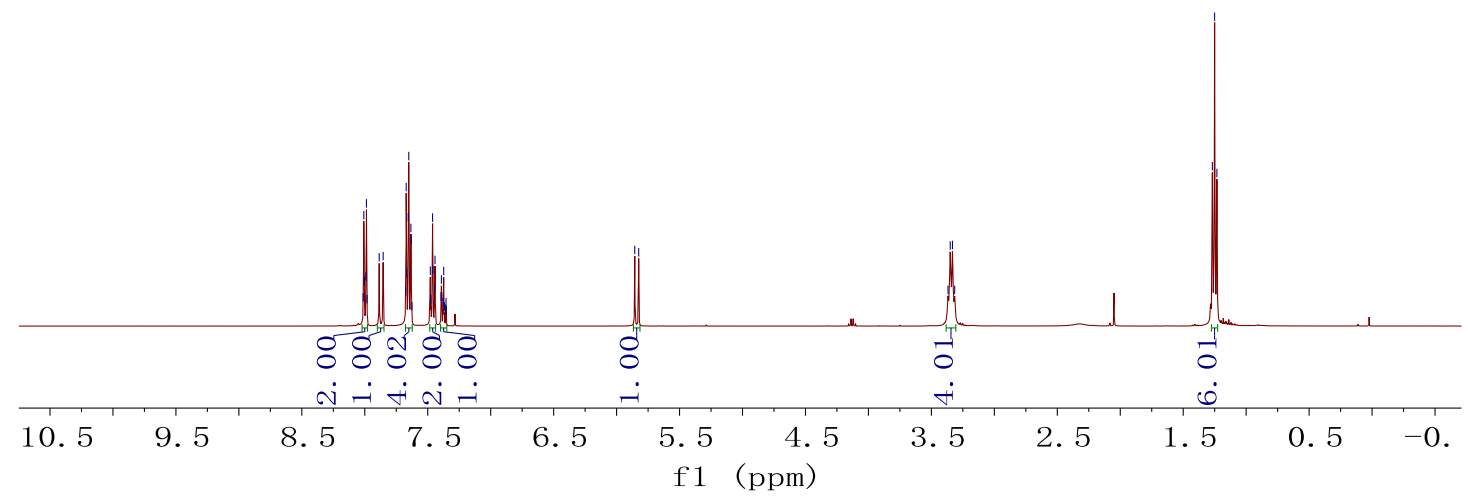

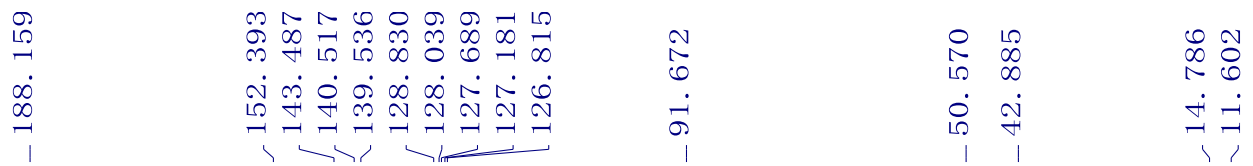

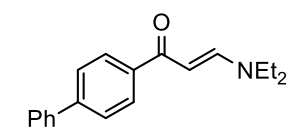

${ }^{13} \mathrm{C}\left\{{ }^{1} \mathrm{H}\right\}$ NMR $\left(101 \mathrm{MHz}, \mathrm{CDCl}_{3}\right)$
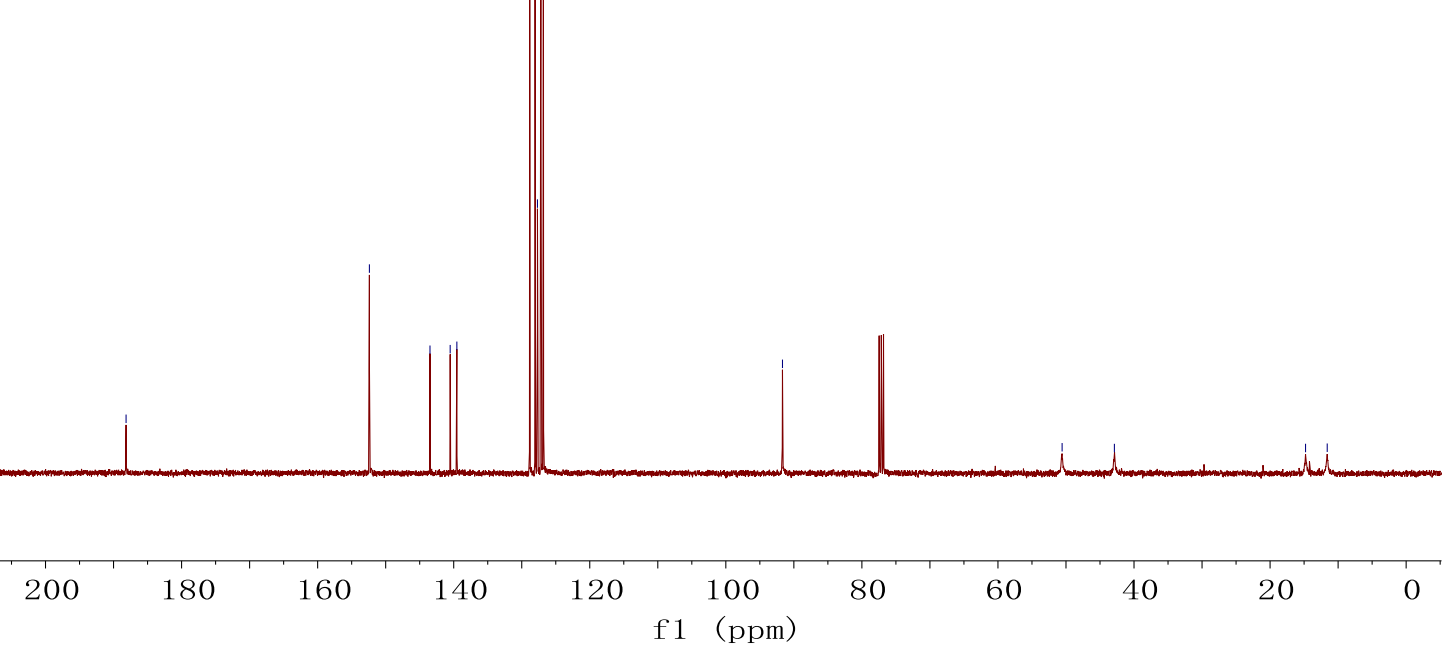
$7 \mathbf{h}$

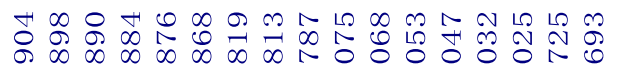

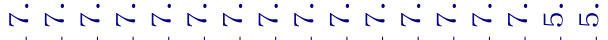

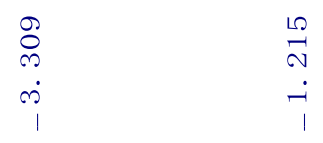

(N)t

${ }^{1} \mathrm{H}$ NMR $\left(400 \mathrm{MHz}, \mathrm{CDCl}_{3}\right)$

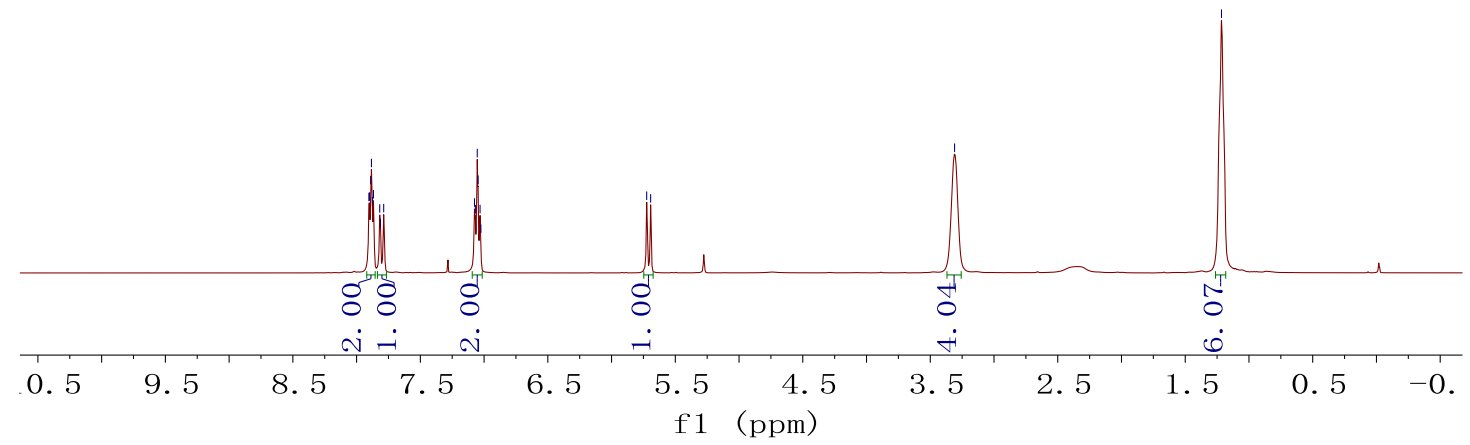

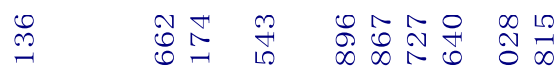

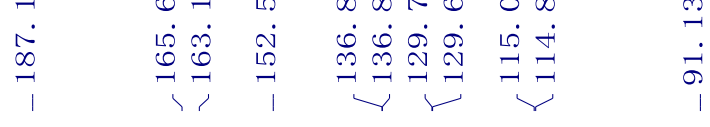

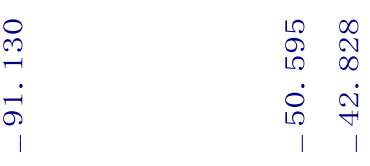

总命

$\dot{+} \dot{\imath}$

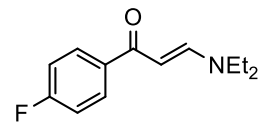

$\left.{ }^{13} \mathrm{C}^{1}{ }^{1} \mathrm{H}\right\} \mathrm{NMR}\left(101 \mathrm{MHz}, \mathrm{CDCl}_{3}\right)$
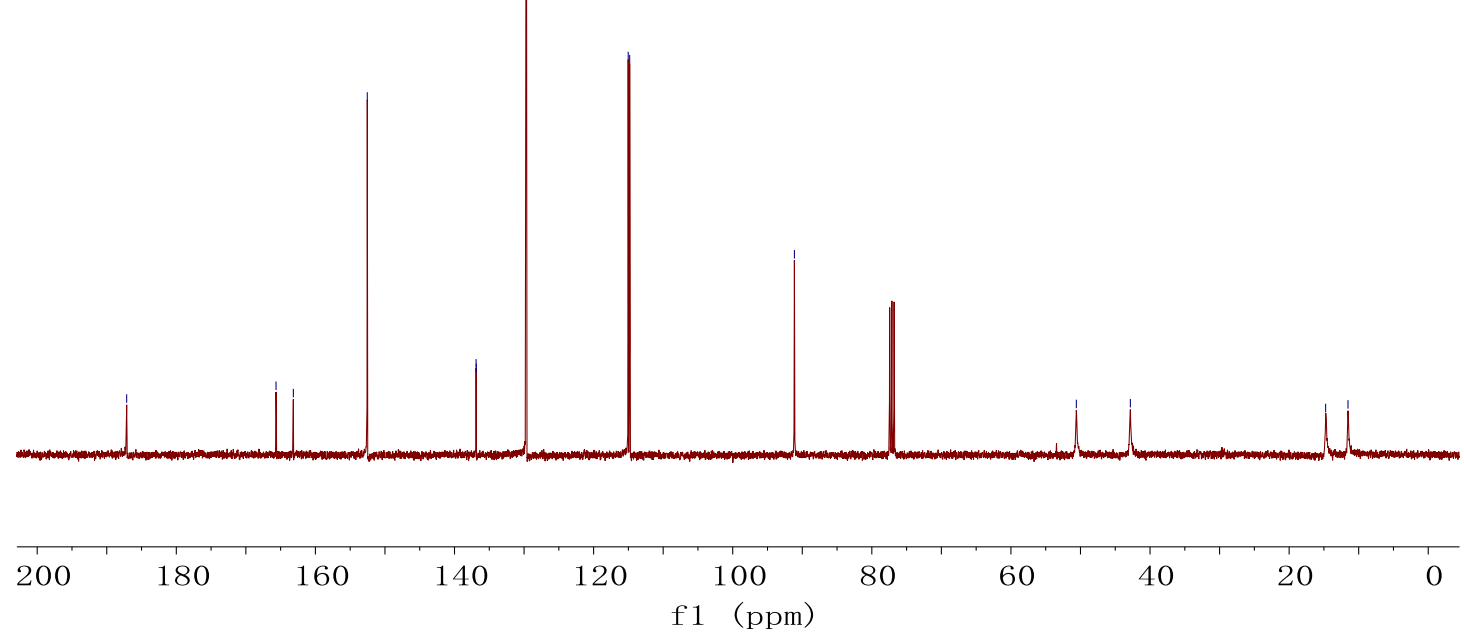


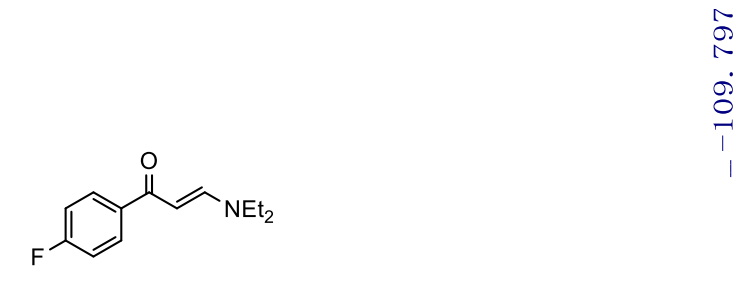

${ }^{19} \mathrm{~F} \mathrm{NMR}\left(376 \mathrm{MHz}, \mathrm{CDCl}_{3}\right)$

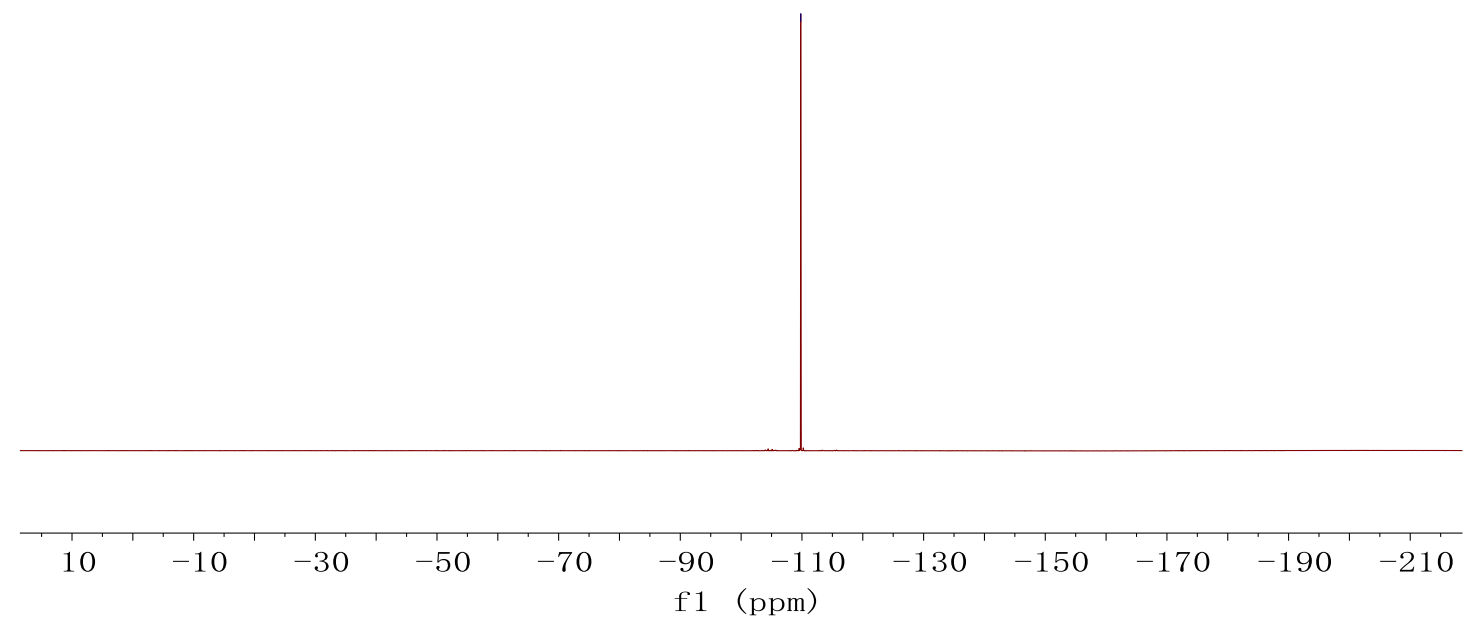


$7 \mathbf{i}$

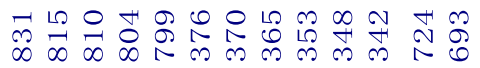

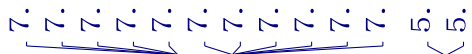

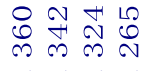

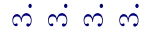

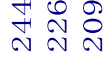

$-\dot{-1}$

(I)

${ }^{1} \mathrm{H}$ NMR $\left(400 \mathrm{MHz}, \mathrm{CDCl}_{3}\right)$

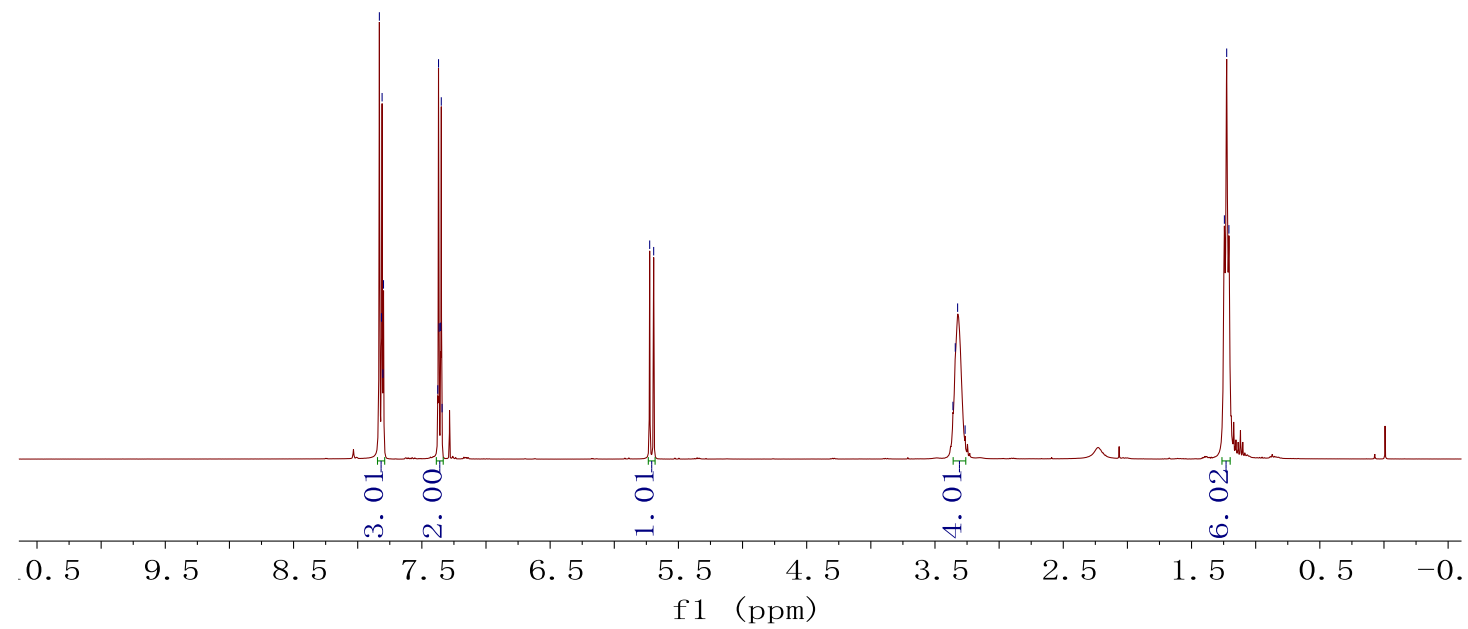

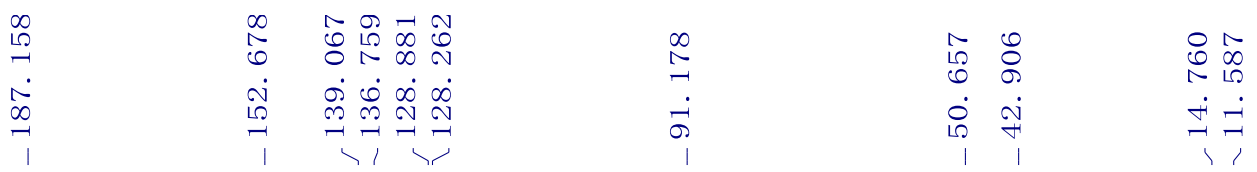<smiles>CCN/C=C/C(=O)c1ccc(Cl)cc1</smiles>

${ }^{13} \mathrm{C}\left\{{ }^{1} \mathrm{H}\right\}$ NMR (101 MHz, $\mathrm{CDCl}_{3}$ )
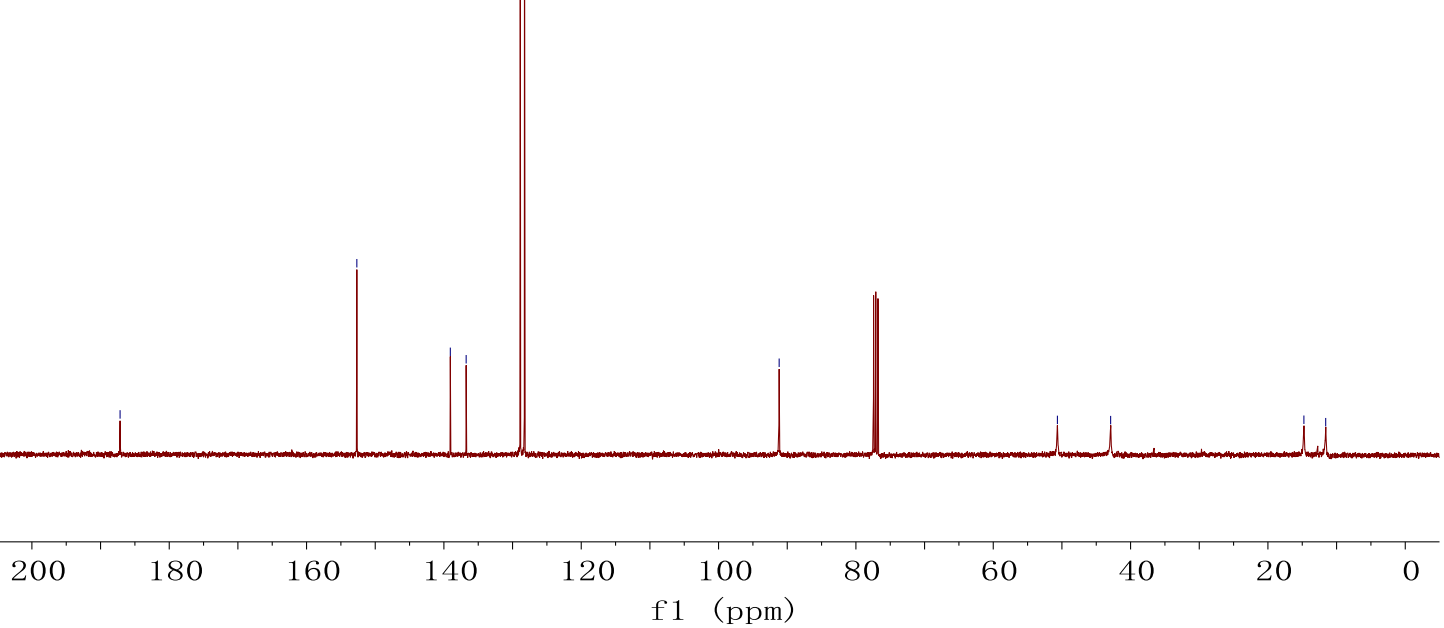
$7 \mathbf{j}$

\begin{tabular}{|c|c|c|}
\hline 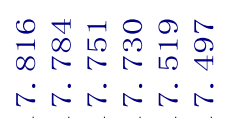 & 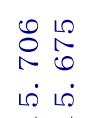 & 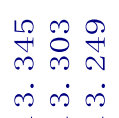 \\
\hline
\end{tabular}<smiles>CCN(C=CC(=O)c1ccc(Br)cc1)CC</smiles>

${ }^{1} \mathrm{H} \mathrm{NMR} \mathrm{(400} \mathrm{MHz,} \mathrm{CDCl}_{3}$ )

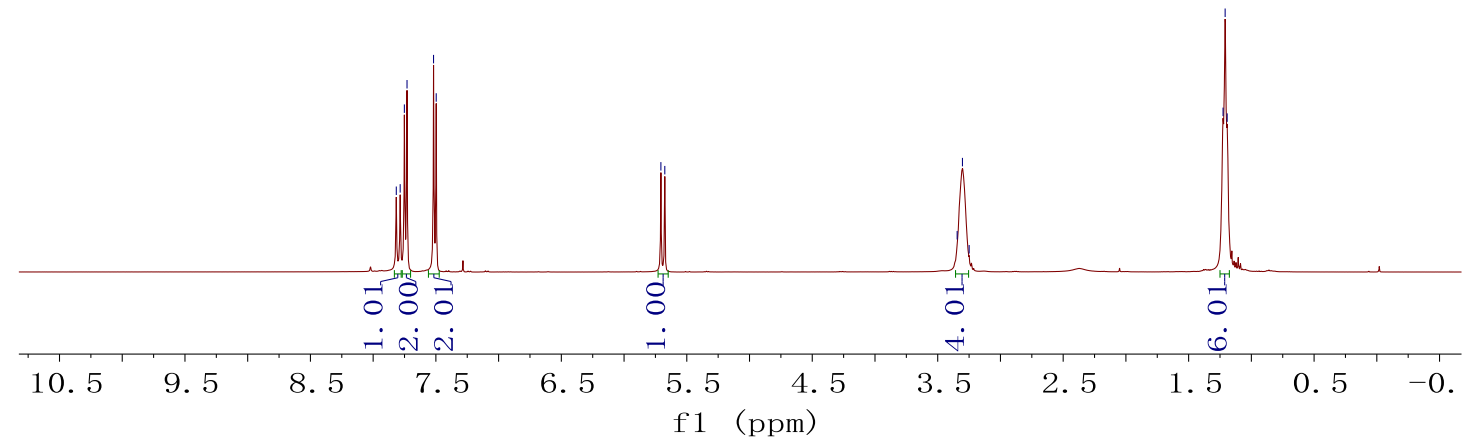

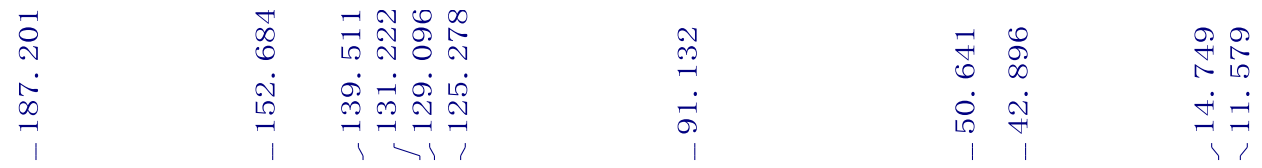<smiles>CCN(C=CC(=O)c1ccc(Br)cc1)CC</smiles>

${ }^{13} \mathrm{C}\left\{{ }^{1} \mathrm{H}\right\} \mathrm{NMR}\left(101 \mathrm{MHz}, \mathrm{CDCl}_{3}\right.$ )
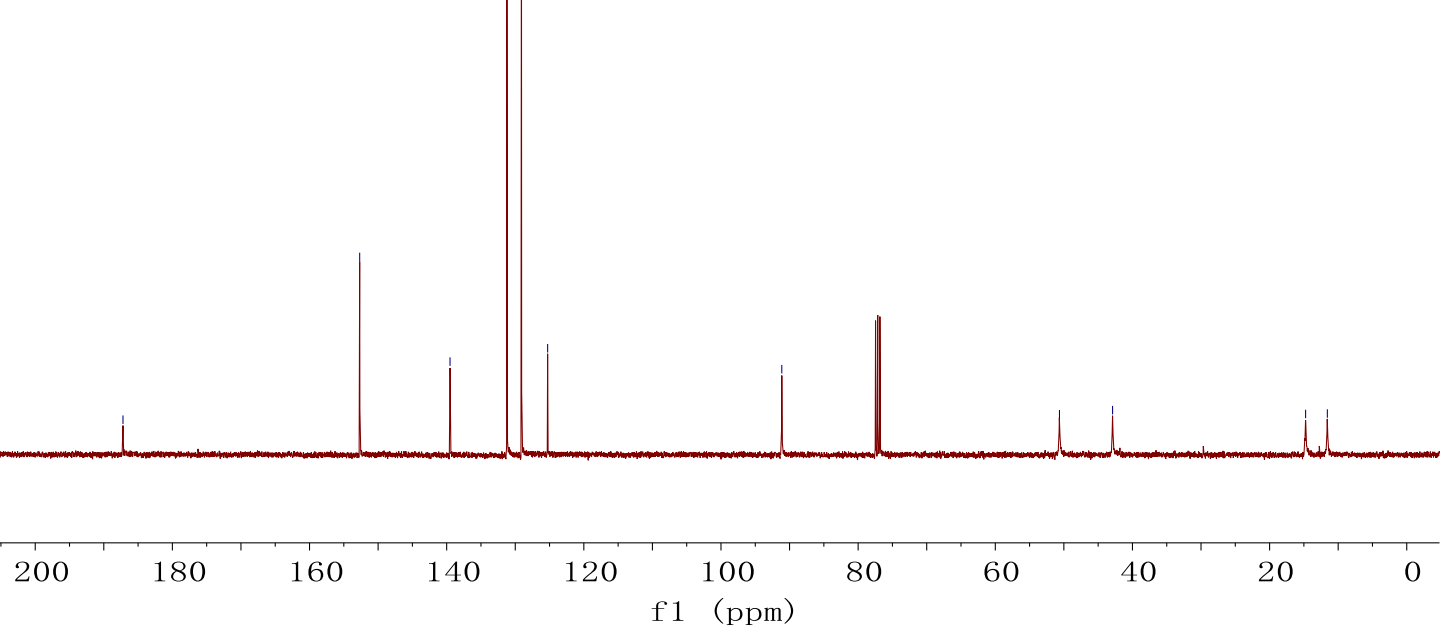
$7 k$

\begin{tabular}{|c|c|c|}
\hline 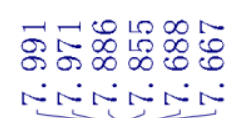 & 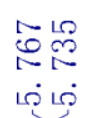 & 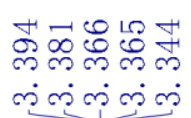 \\
\hline
\end{tabular}<smiles>CCN=CC(=O)c1ccc(C(F)(F)F)cc1</smiles>

${ }^{1} \mathrm{H}$ NMR (400 MHz, $\mathrm{CDCl}_{3}$ )
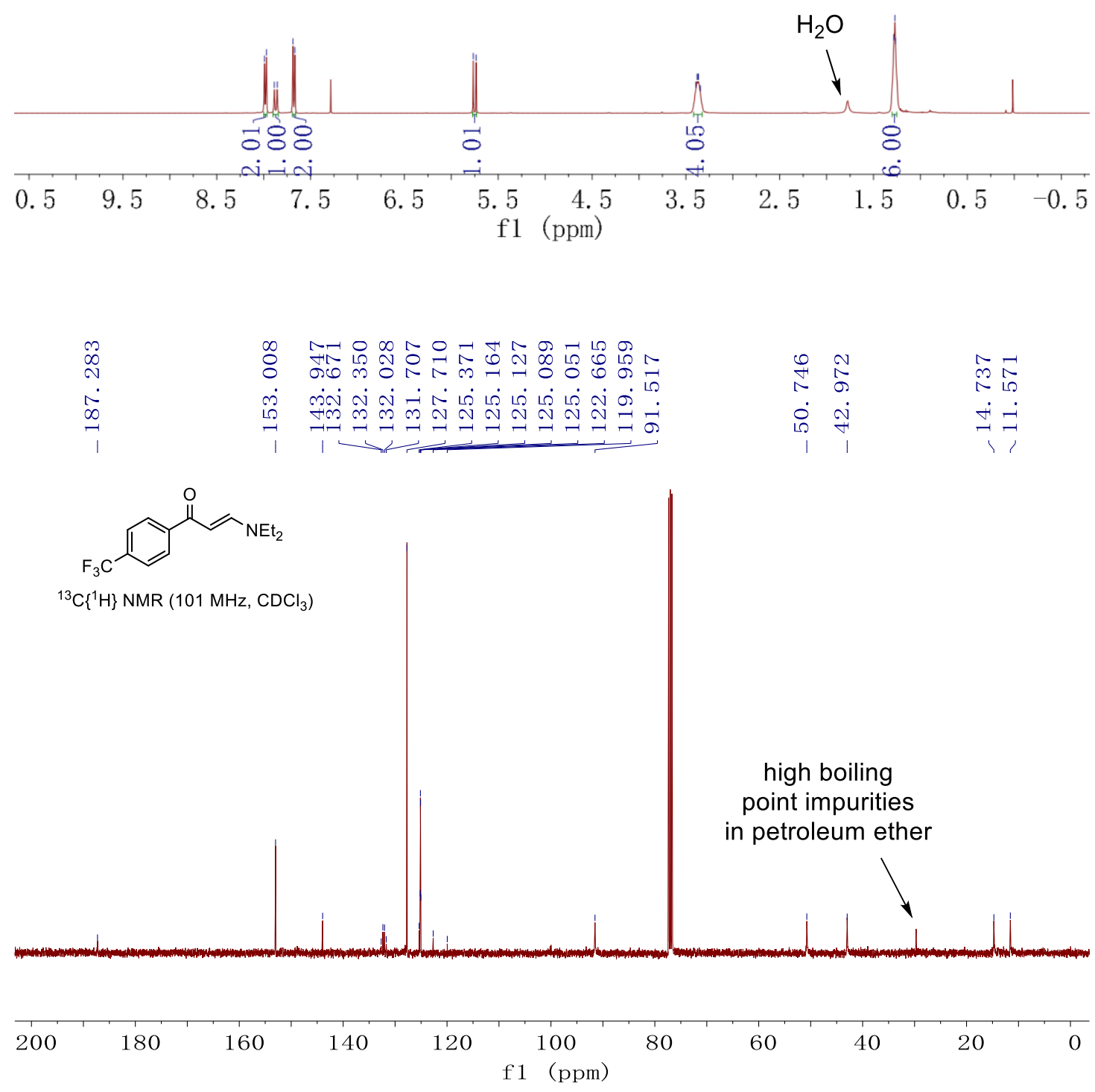


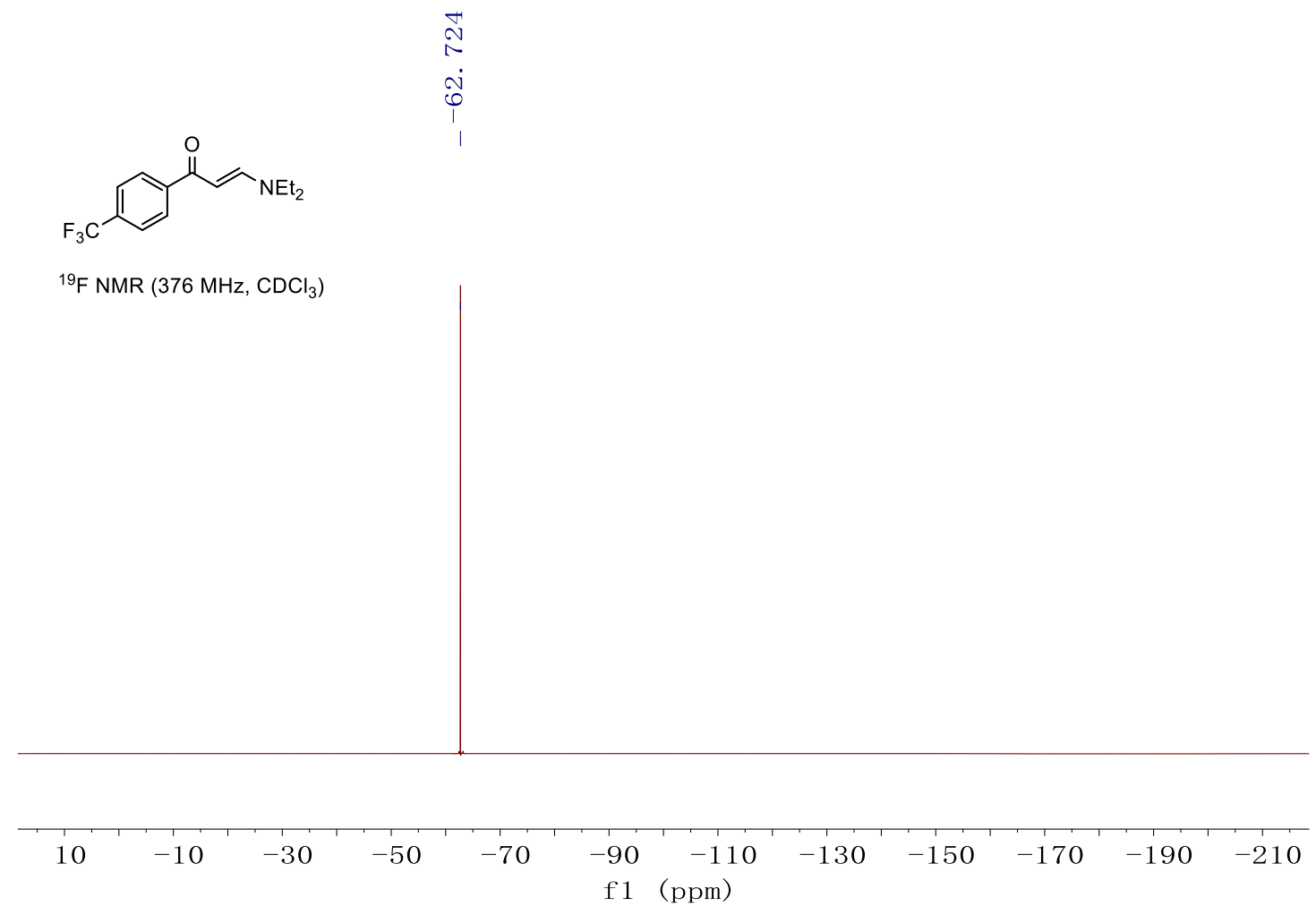


71

\begin{tabular}{|c|c|c|c|}
\hline 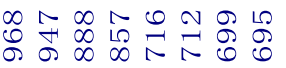 & $\begin{array}{l}+\infty \\
\infty\end{array}$ & 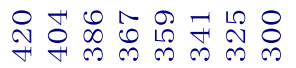 & 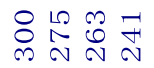 \\
\hline 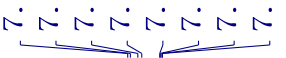 & & $\dot{r} \dot{r} \dot{r} \dot{r} \dot{r} \dot{n}$ & $\dot{-1}$ \\
\hline
\end{tabular}<smiles>CCN(C=CC(=O)c1ccc(N)cc1)CC</smiles>

${ }^{1} \mathrm{H}$ NMR $\left(400 \mathrm{MHz}, \mathrm{CDCl}_{3}\right)$

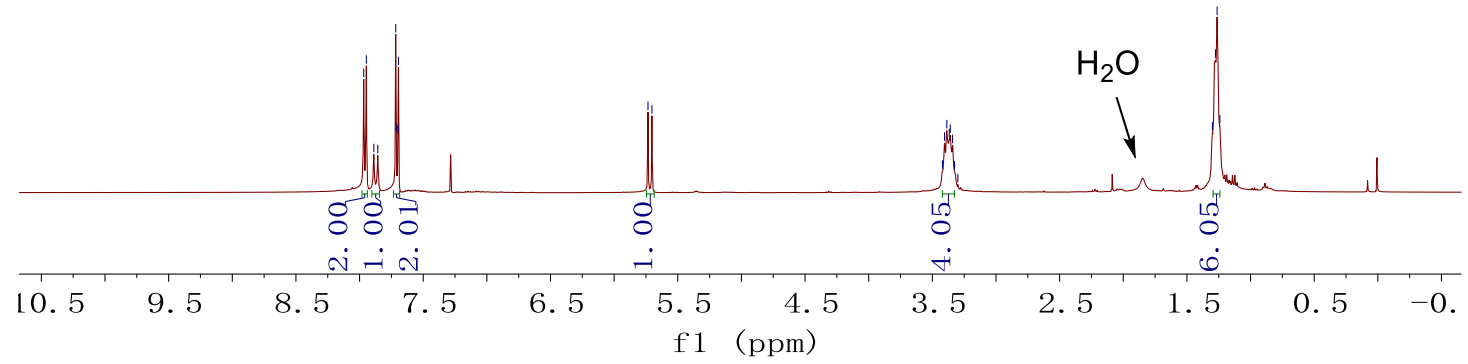

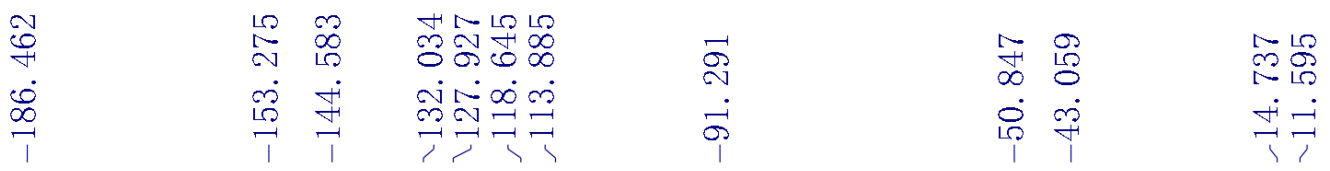<smiles></smiles>

${ }^{13} \mathrm{C}\left\{{ }^{1} \mathrm{H}\right\} \mathrm{NMR}\left(101 \mathrm{MHz}, \mathrm{CDCl}_{3}\right)$

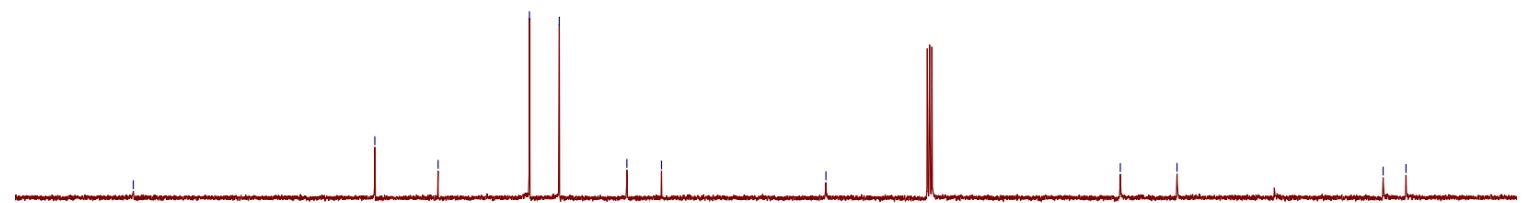

\begin{tabular}{|c|c|c|c|c|c|c|c|}
\hline 300 & 180 & 160 & 140 & 120 & $\begin{array}{c}100 \\
1 \quad(\mathrm{ppm})\end{array}$ & 80 & 20 \\
\hline
\end{tabular}




\section{$7 \mathbf{m}$}

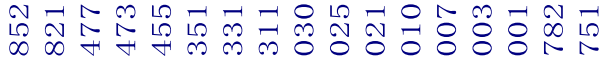

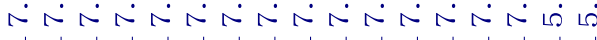

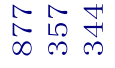

$\dot{\omega} \dot{\text { ले }}$

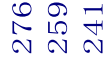

- $-\dot{-1}$<smiles>CCN(C=CC(=O)c1cccc(OC)c1)CC</smiles>

${ }^{1} \mathrm{H} \mathrm{NMR}\left(400 \mathrm{MHz}, \mathrm{CDCl}_{3}\right)$

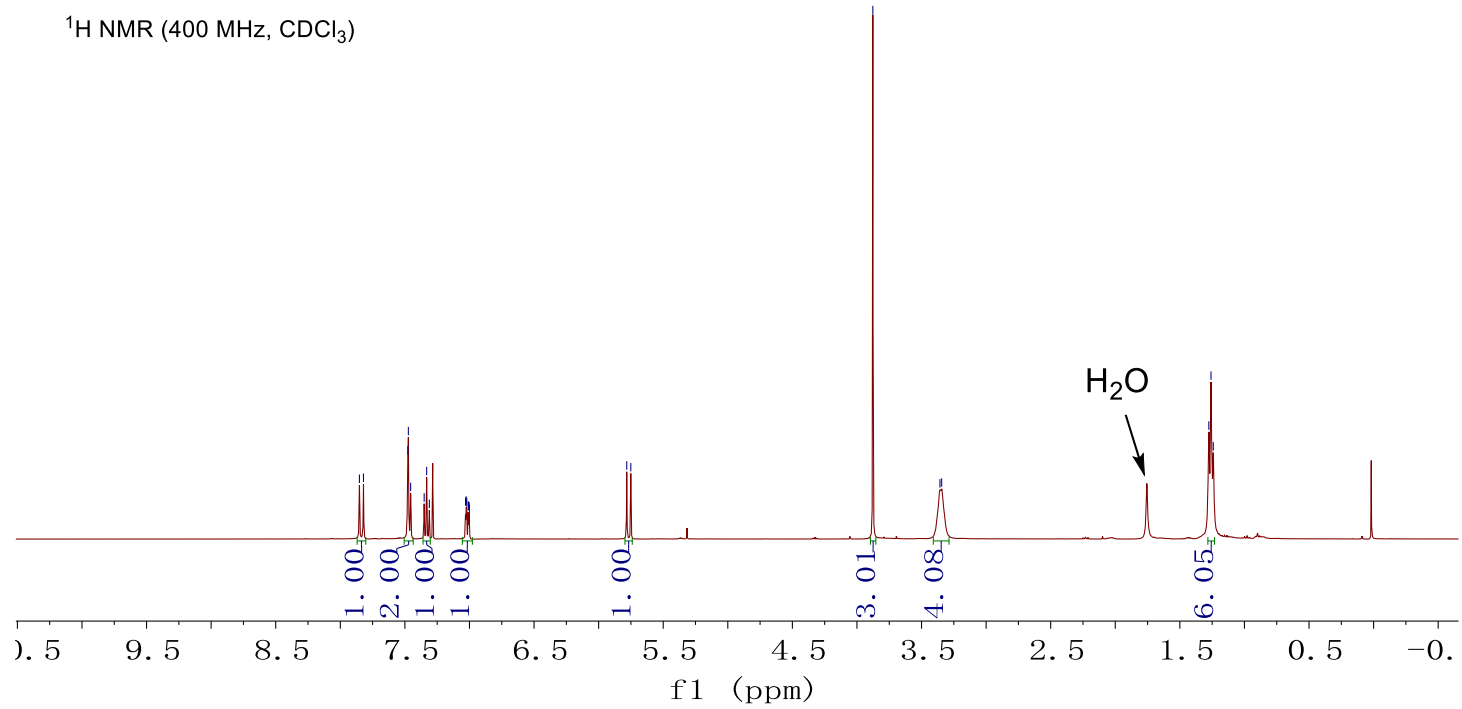

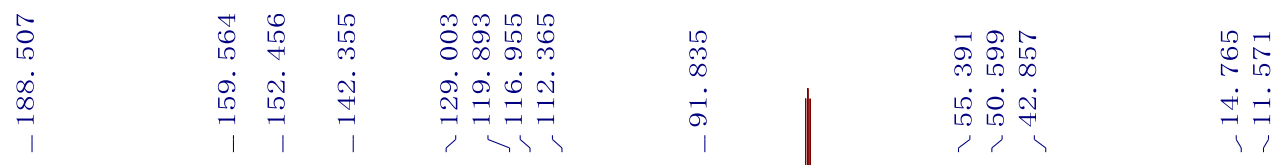<smiles>CCN(C=CC(=O)c1cccc(OC)c1)CC</smiles>

${ }^{13} \mathrm{C}\left\{{ }^{1} \mathrm{H}\right\}$ NMR $\left(101 \mathrm{MHz}, \mathrm{CDCl}_{3}\right)$

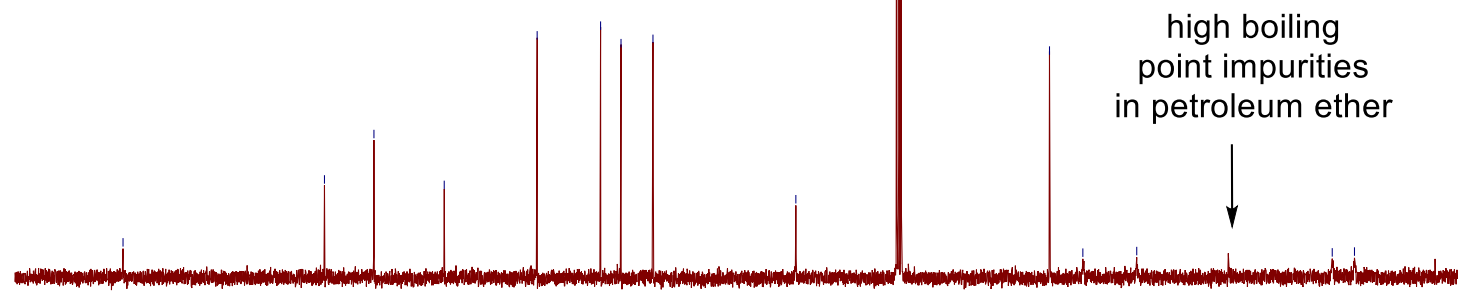

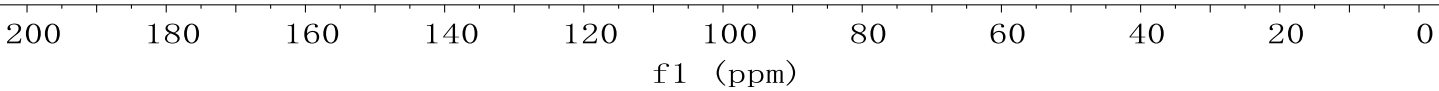


$7 \mathbf{n}$

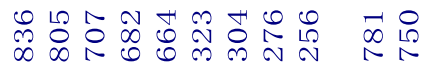

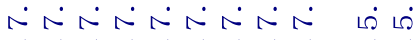<smiles>CCN(C=CC(=O)c1cccc(C)c1)CC</smiles>

${ }^{1} \mathrm{H}$ NMR (400 MHz, $\left.\mathrm{CDCl}_{3}\right)$

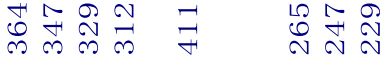

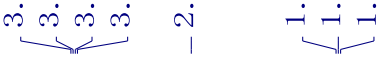

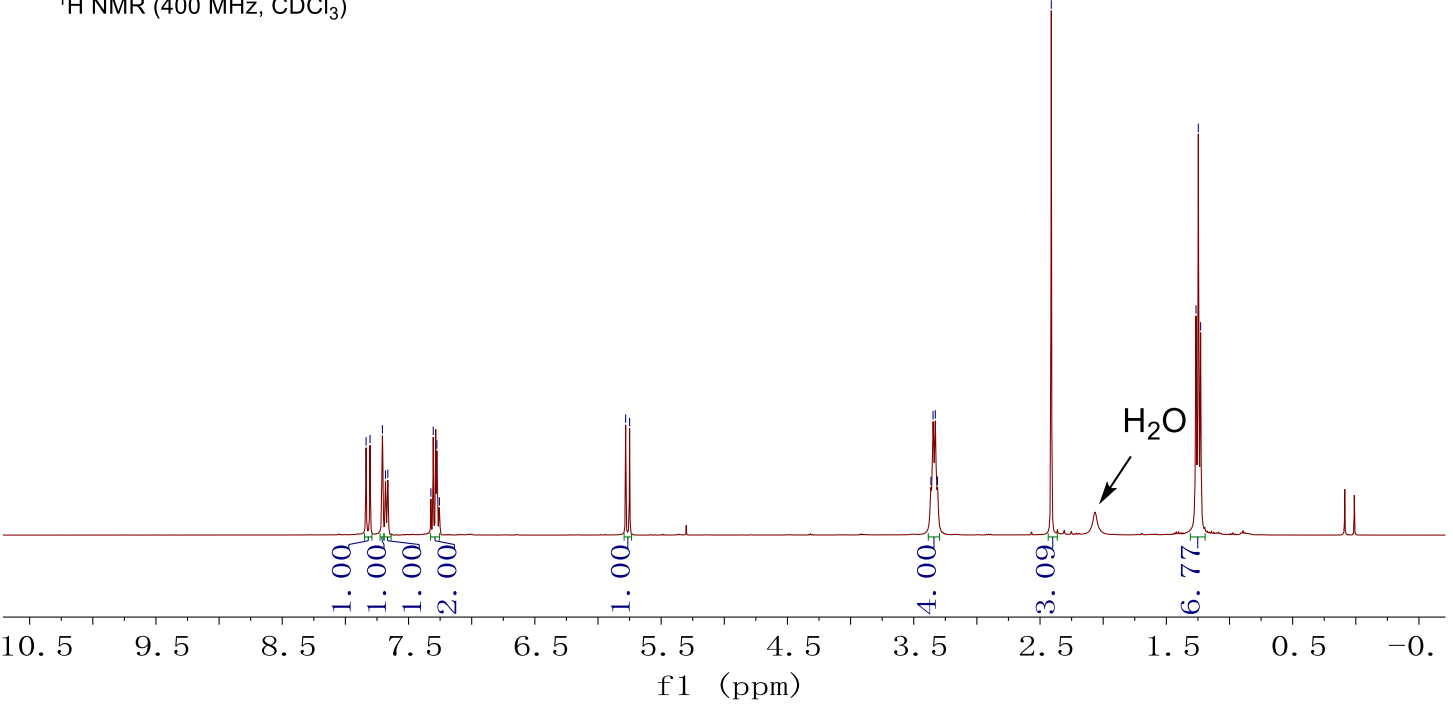

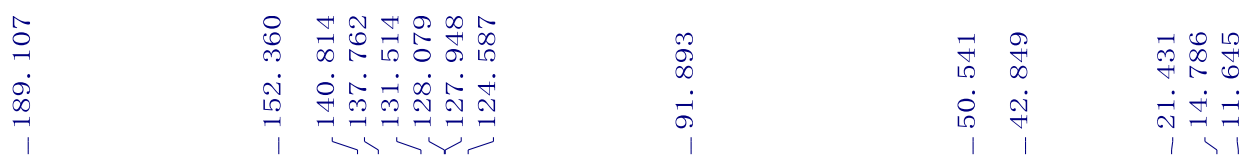<smiles>CCN(C=CC(=O)c1cccc(C)c1)CC</smiles>

${ }^{13} \mathrm{C}\left\{{ }^{1} \mathrm{H}\right\}$ NMR $\left(101 \mathrm{MHz}, \mathrm{CDCl}_{3}\right)$

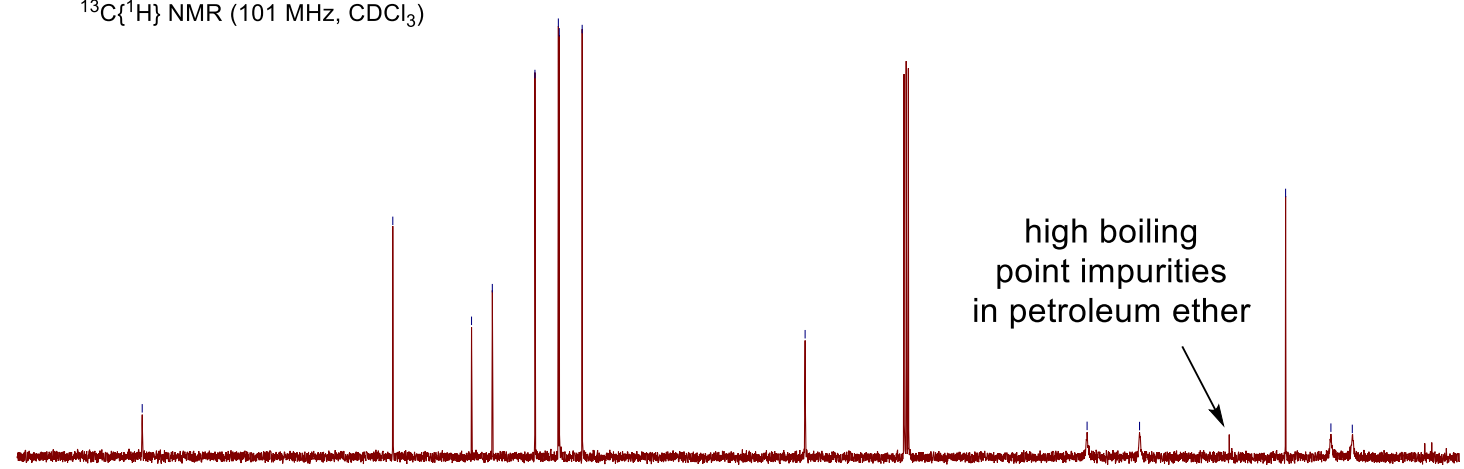

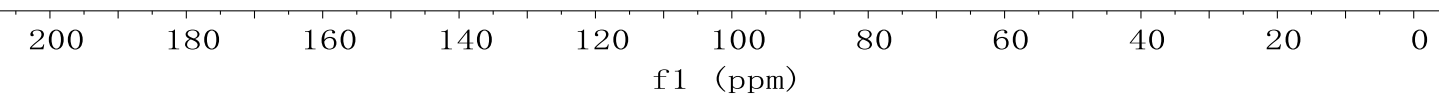


70

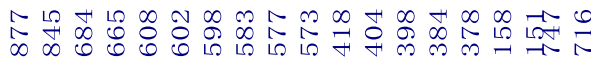

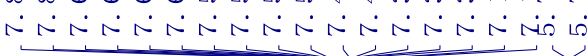

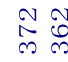

$\ddot{n}$

$\stackrel{N}{N}$<smiles>CCN/C=C/C(=O)c1cccc(F)c1</smiles>

${ }^{1} \mathrm{H} \mathrm{NMR}\left(400 \mathrm{MHz}, \mathrm{CDCl}_{3}\right)$

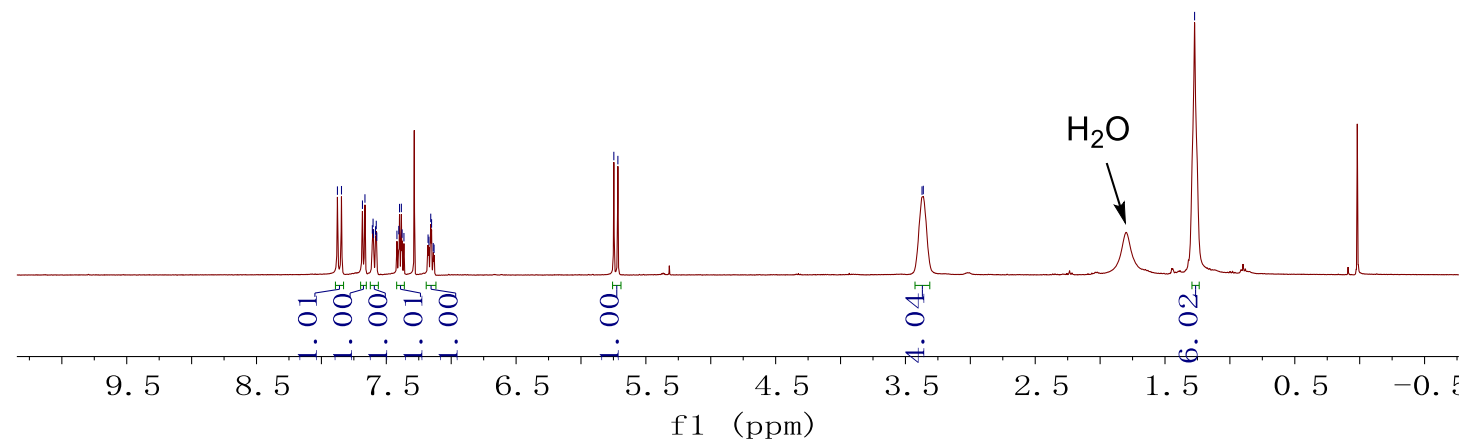

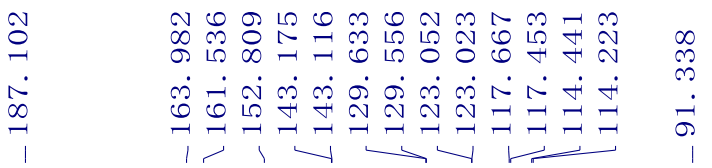

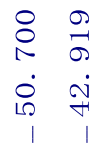

$\stackrel{\sim}{\sim} \underset{\sim}{\stackrel{2}{L}}$<smiles>CCN=CC=C(C)c1cccc(F)c1</smiles>

${ }^{13} \mathrm{C}\left\{{ }^{1} \mathrm{H}\right\}$ NMR $\left(101 \mathrm{MHz}, \mathrm{CDCl}_{3}\right)$

high boiling

point impurities

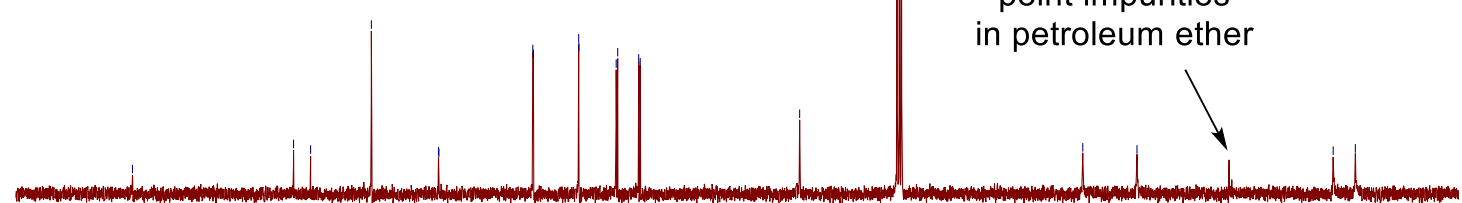

200

180

160

140

120

100

80

f1 (ppm) 


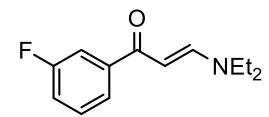

${ }^{19} \mathrm{~F}$ NMR $\left(376 \mathrm{MHz}, \mathrm{CDCl}_{3}\right.$ )

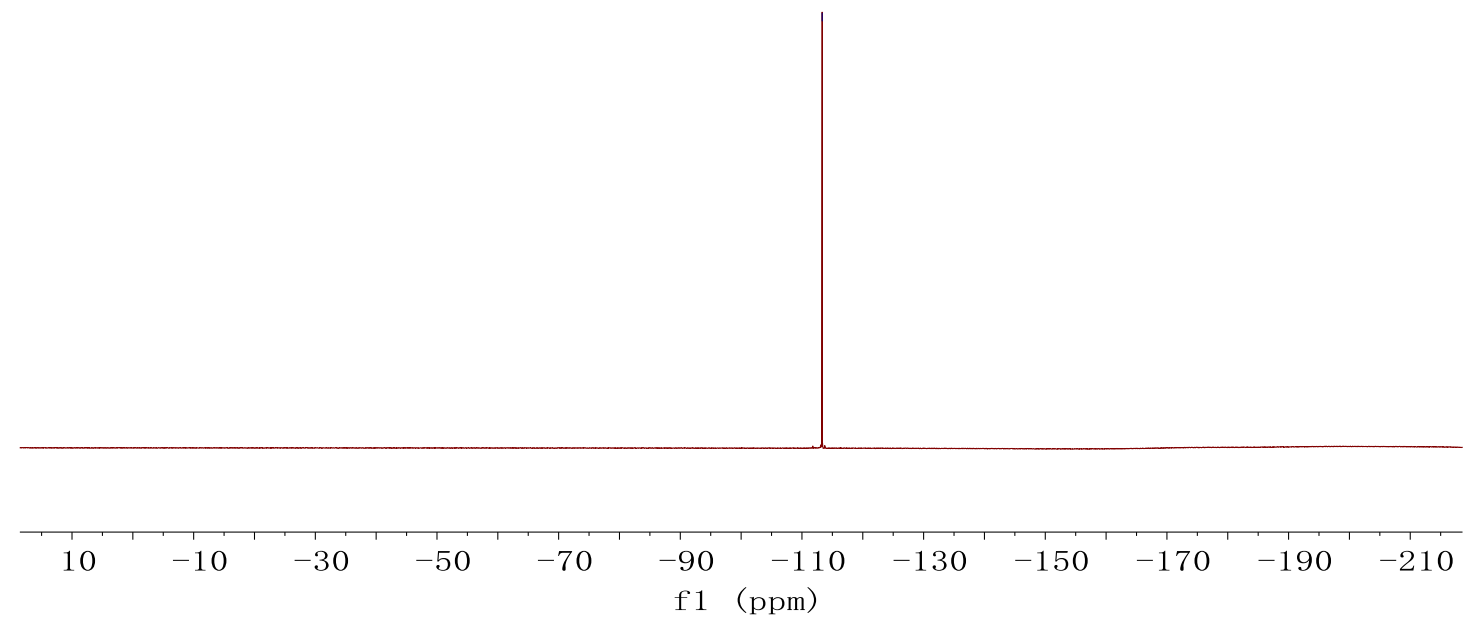


$7 p$

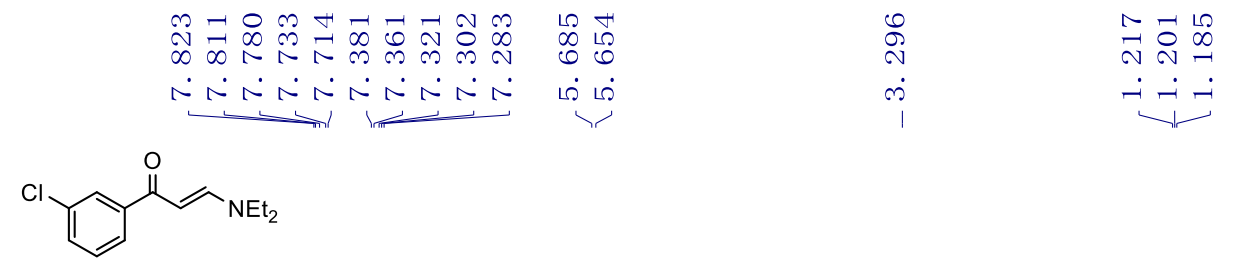

${ }^{1} \mathrm{H}$ NMR $\left(400 \mathrm{MHz}, \mathrm{CDCl}_{3}\right)$

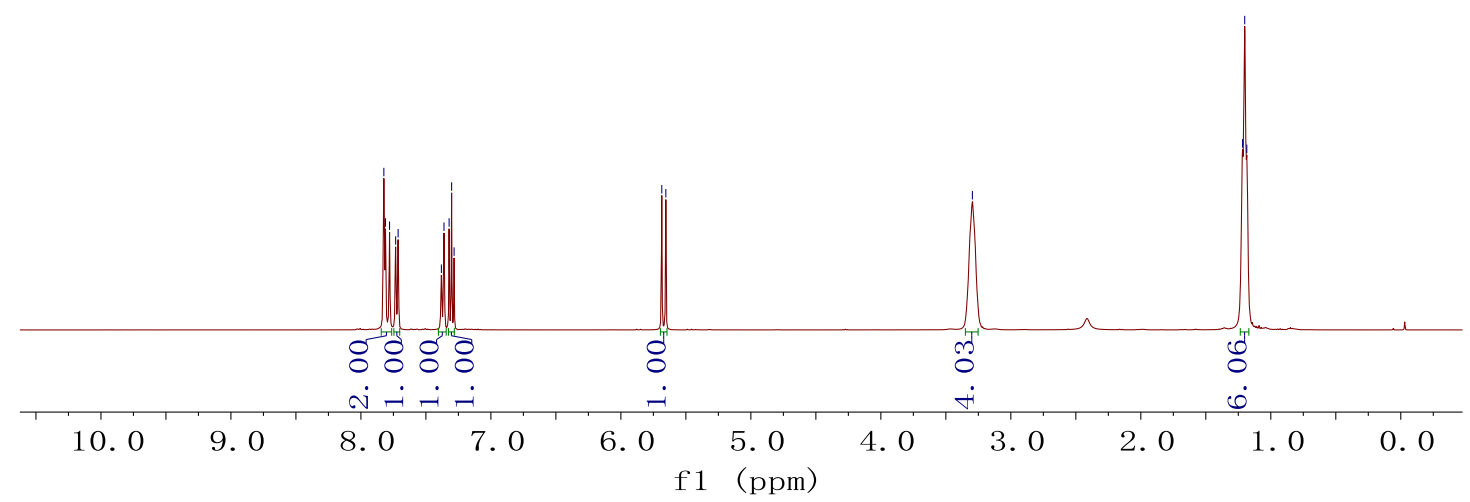

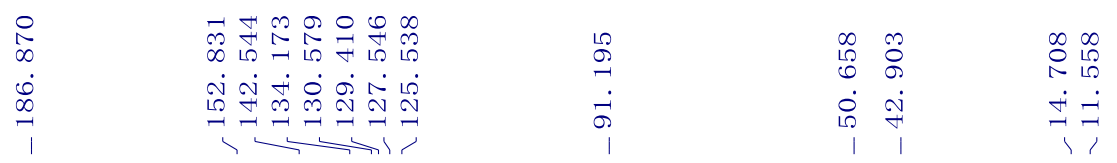<smiles>CCN(C=CC(=O)c1cccc(Cl)c1)CC</smiles>

${ }^{13} \mathrm{C}\left\{{ }^{1} \mathrm{H}\right\} \mathrm{NMR}\left(101 \mathrm{MHz}, \mathrm{CDCl}_{3}\right)$

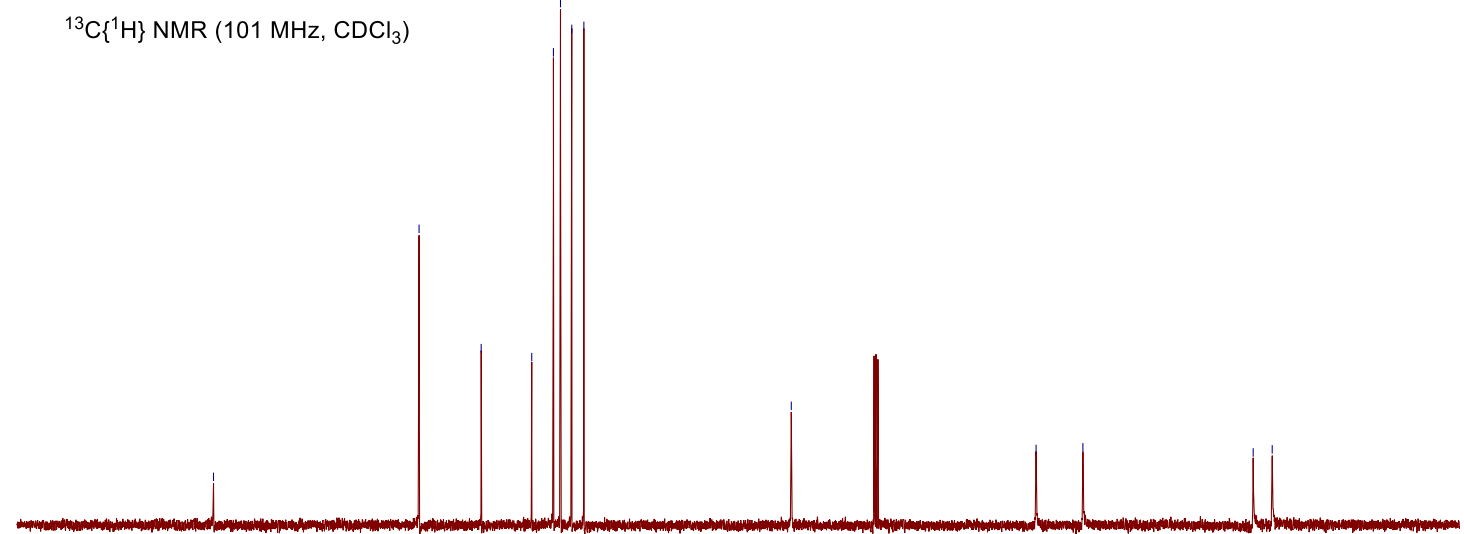

$\begin{array}{lllllllllll}210 & 190 & 170 & 150 & 130 & \begin{array}{c}110 \\ \mathrm{f} 1\end{array}\left(\begin{array}{cc}90 \\ (\mathrm{ppm})\end{array}\right. & 70 & 50 & 30 & 10 & -10\end{array}$


$7 q$

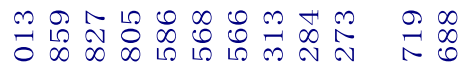

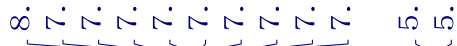

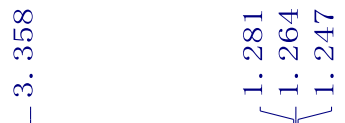<smiles>CCN(C=CC(=O)c1cccc(Br)c1)CC</smiles>

${ }^{1} \mathrm{H} \mathrm{NMR}\left(400 \mathrm{MHz}, \mathrm{CDCl}_{3}\right)$
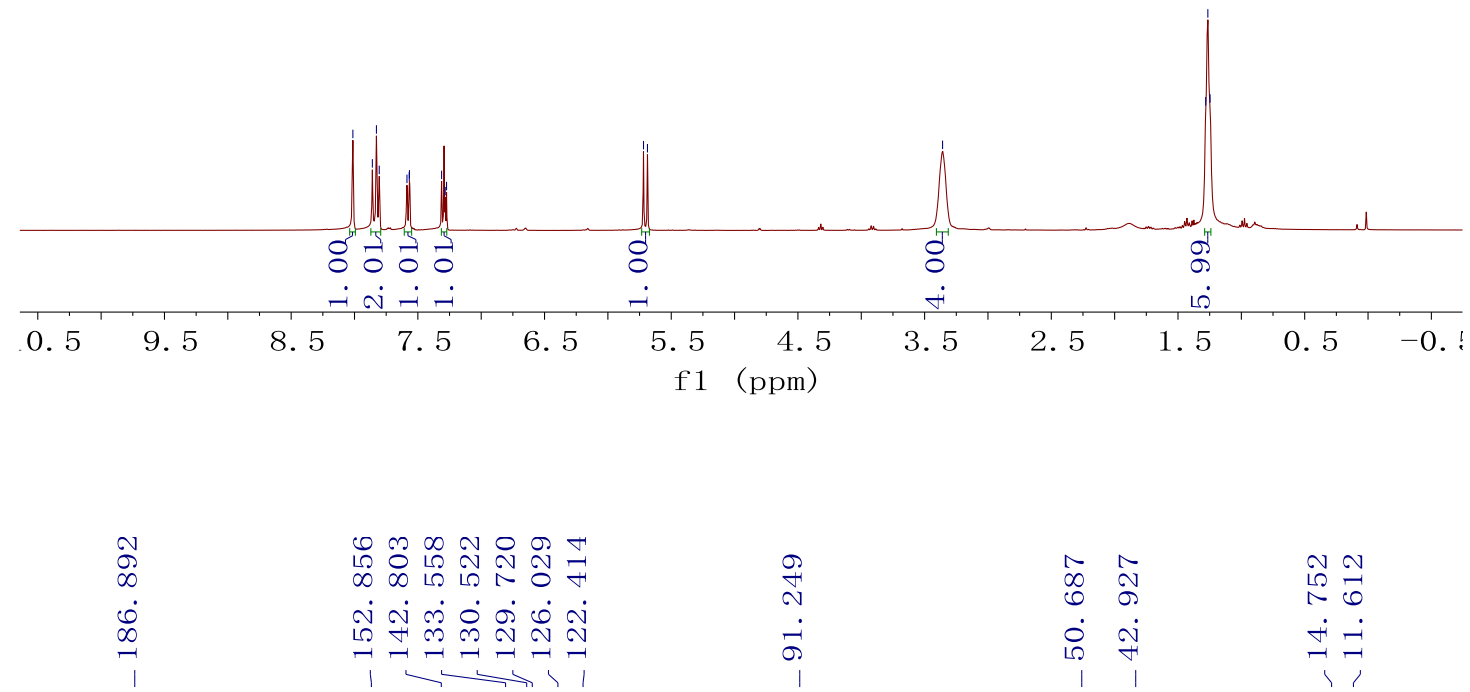<smiles>CCN(C=CC(=O)c1cccc(Br)c1)CC</smiles>

${ }^{13} \mathrm{C}\left\{{ }^{1} \mathrm{H}\right\} \mathrm{NMR}\left(101 \mathrm{MHz}, \mathrm{CDCl}_{3}\right)$

high boiling point impurities in petroleum ether

\begin{tabular}{lllllllllll}
\hline 200 & 180 & 160 & 140 & 120 & $\begin{array}{c}100 \\
\mathrm{f} 1\end{array}(\mathrm{ppm})$ & 80 & 60 & 40 & 20 & 0
\end{tabular}


$7 \mathbf{r}$

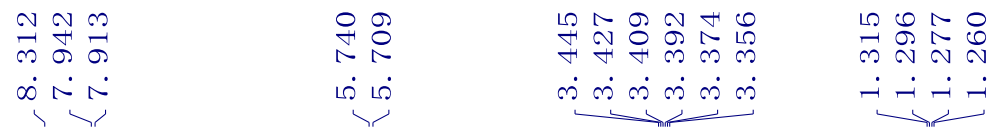<smiles>CCN=CC=C(c1cc(C(F)(F)F)cc(C(F)(F)F)c1)C(F)(F)F</smiles>

${ }^{1} \mathrm{H}$ NMR $\left(400 \mathrm{MHz}, \mathrm{CDCl}_{3}\right)$

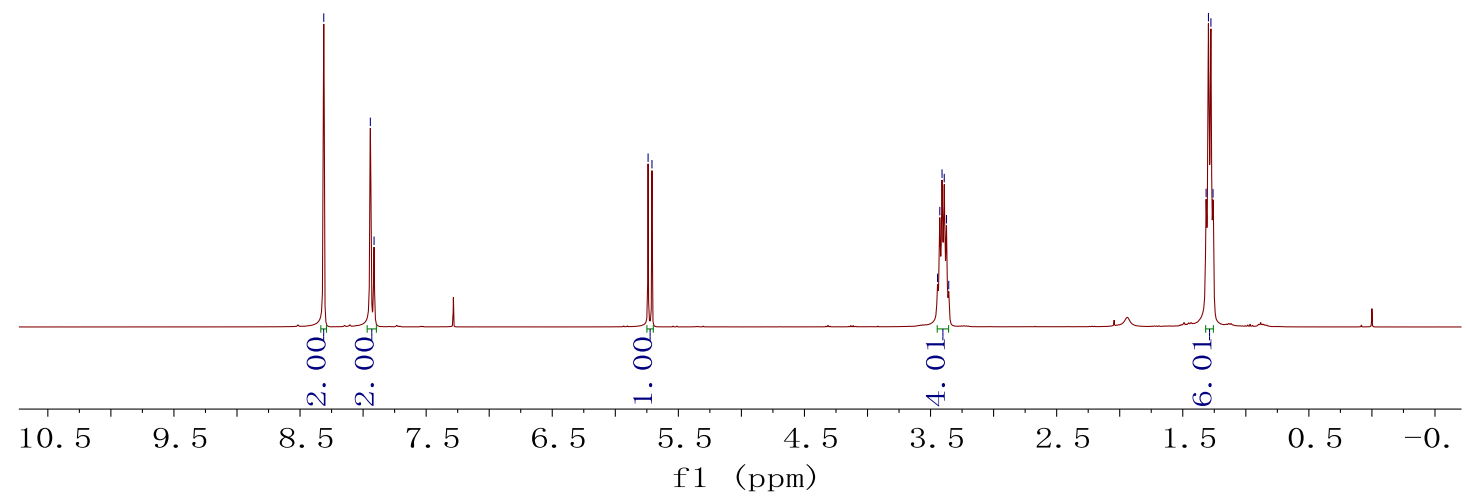

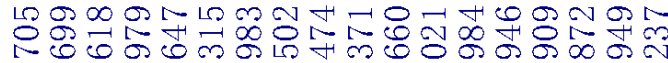

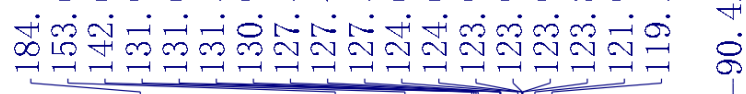

$\stackrel{2}{\circ}$

$8 \underset{0}{8}$

$\dot{0} \dot{\sim}$

迎<smiles>CCN=CC=C(c1cc(C(F)(F)F)cc(C(F)(F)F)c1)C(F)(F)F</smiles>

${ }^{13} \mathrm{C}\left\{{ }^{1} \mathrm{H}\right\}$ NMR $\left(101 \mathrm{MHz}, \mathrm{CDCl}_{3}\right)$

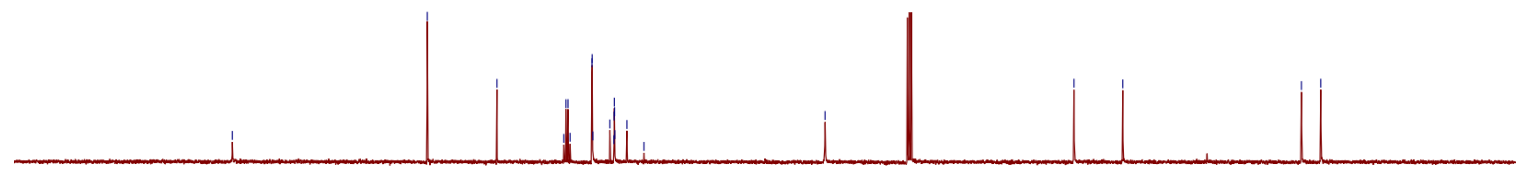

\begin{tabular}{|c|c|c|c|c|c|c|c|c|c|c|c|}
\hline 210 & 190 & 170 & 150 & 130 & $\begin{array}{c}110 \\
\mathrm{f} 1\end{array}$ & $\begin{array}{l}90 \\
\text { om) }\end{array}$ & 70 & 50 & 30 & 10 & -10 \\
\hline
\end{tabular}




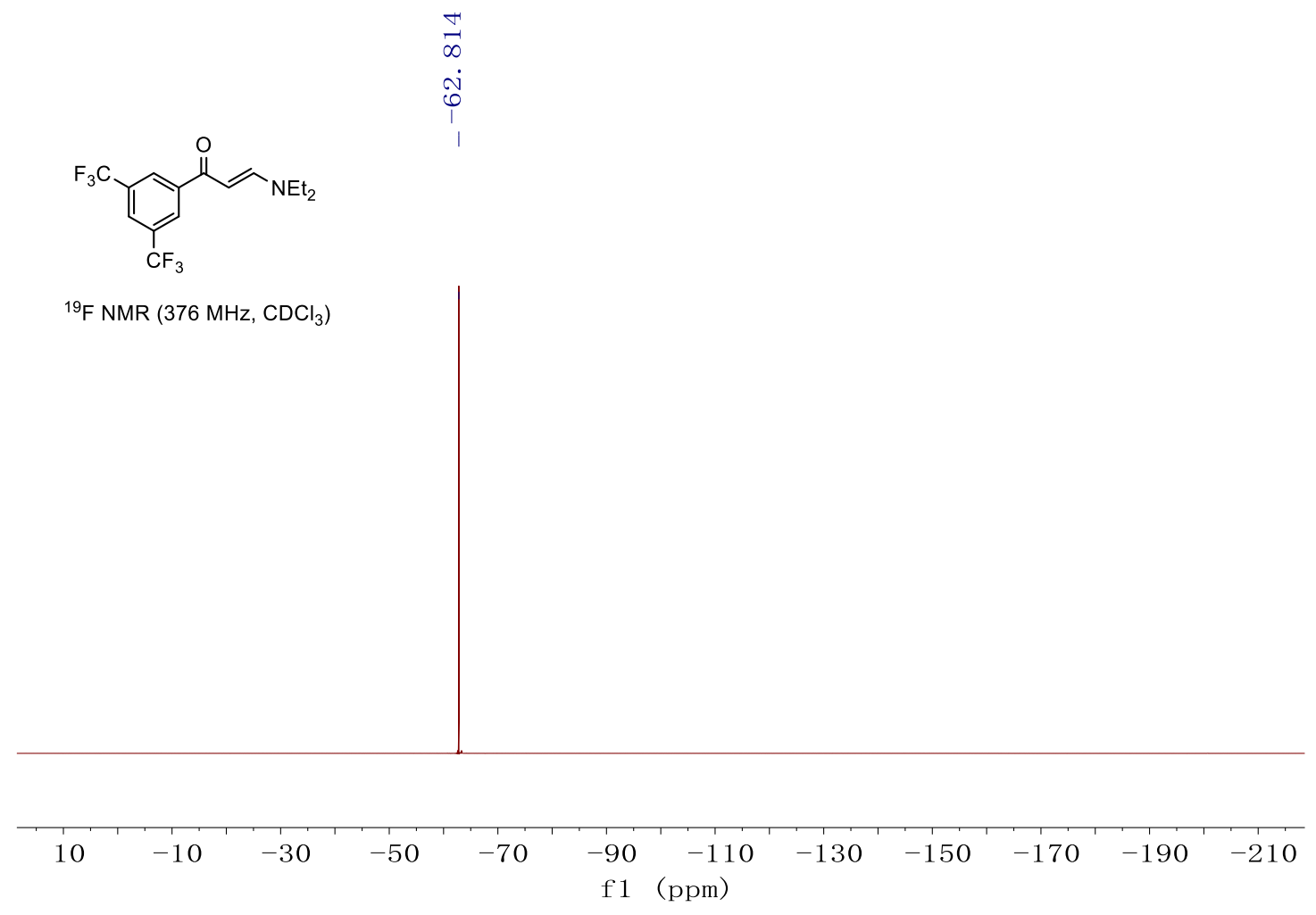




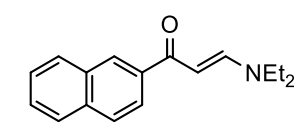

${ }^{1} \mathrm{H}$ NMR $\left(400 \mathrm{MHz}, \mathrm{CDCl}_{3}\right)$
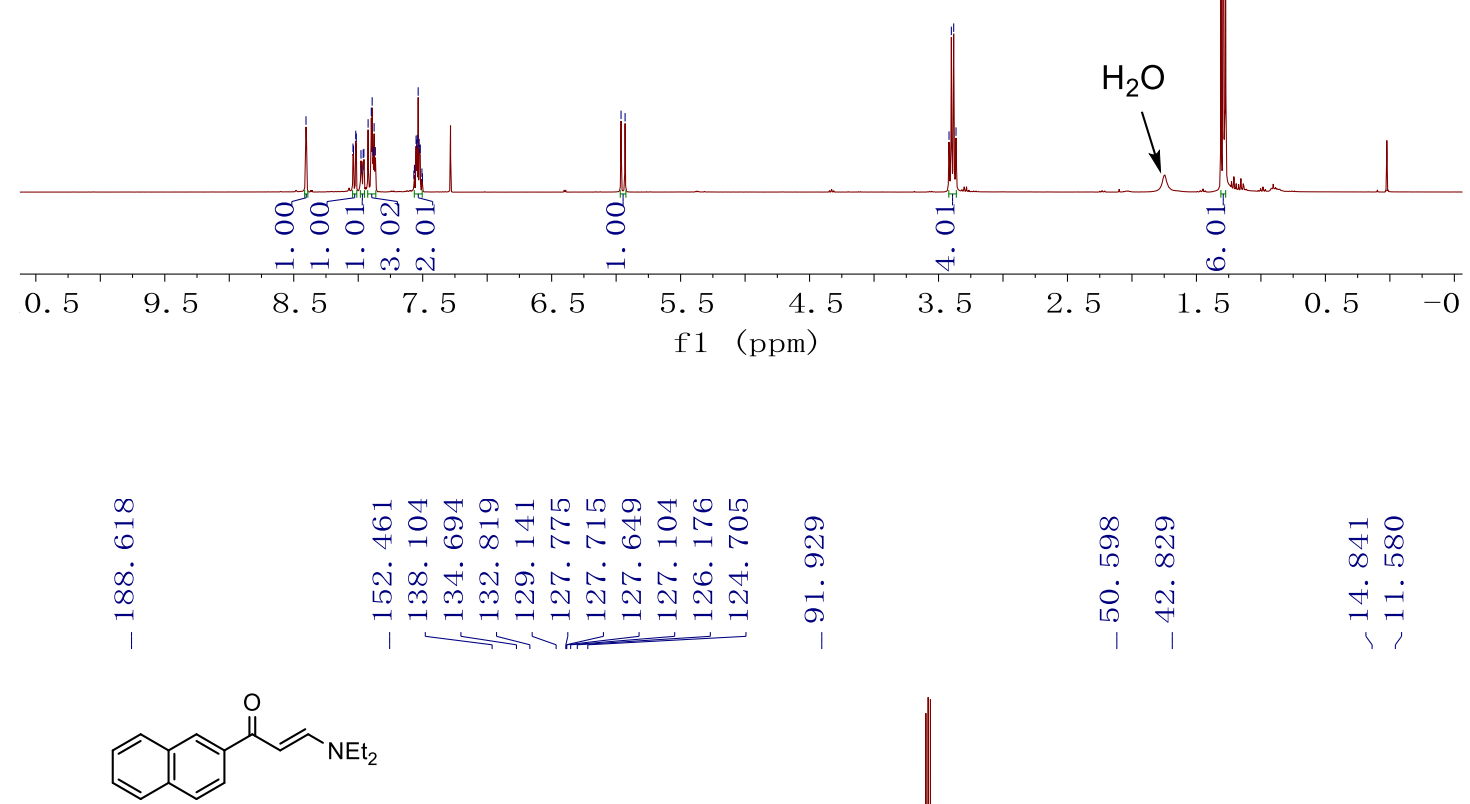

${ }^{13} \mathrm{C}\left\{{ }^{1} \mathrm{H}\right\}$ NMR $\left(101 \mathrm{MHz}, \mathrm{CDCl}_{3}\right)$

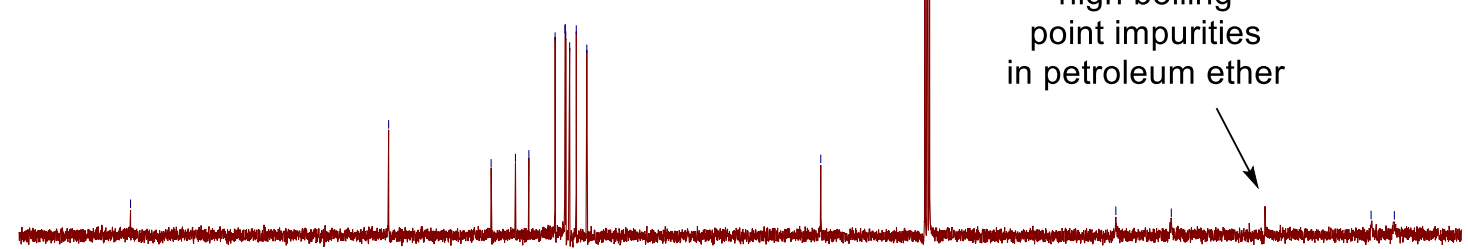

high boiling point impurities

in petroleum ether

\begin{tabular}{|c|c|c|c|c|c|c|c|c|c|}
\hline 190 & 170 & 150 & 130 & $\begin{array}{l}110 \\
\mathrm{f} 1\end{array}$ & 90 & 70 & 50 & 30 & 10 \\
\hline
\end{tabular}




\section{7w}

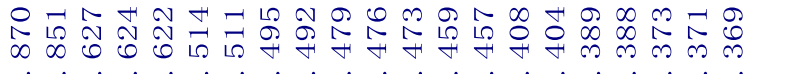

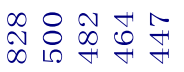

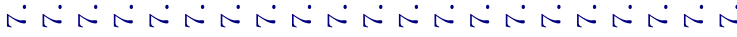

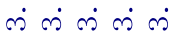

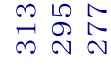

-<smiles>CCN=CC1=Cc2ccccc2C1=O</smiles>

${ }^{1} \mathrm{H}$ NMR $\left(400 \mathrm{MHz}, \mathrm{CDCl}_{3}\right)$
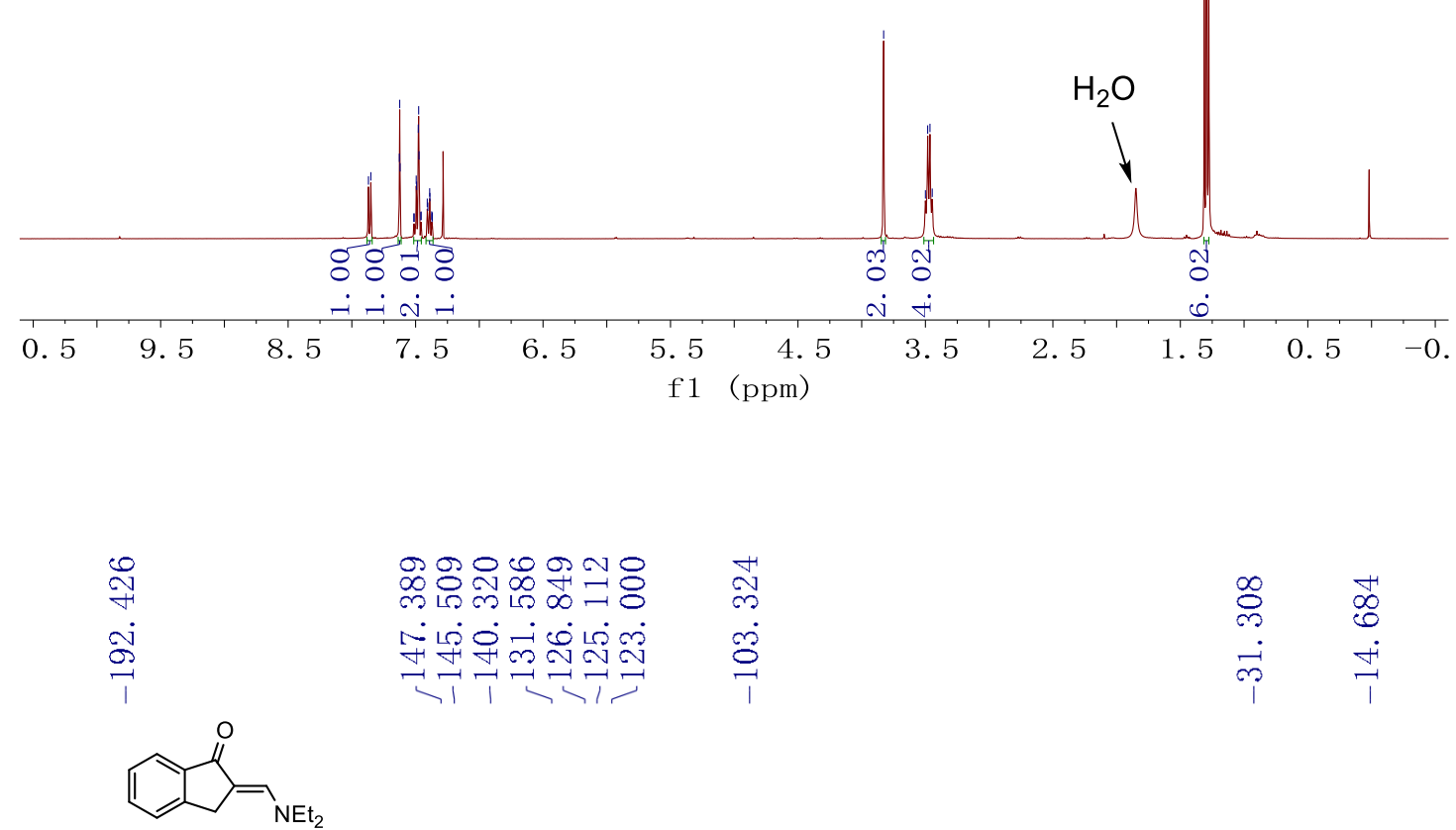

${ }^{13} \mathrm{C}\left\{{ }^{1} \mathrm{H}\right\}$ NMR $\left(101 \mathrm{MHz}, \mathrm{CDCl}_{3}\right)$

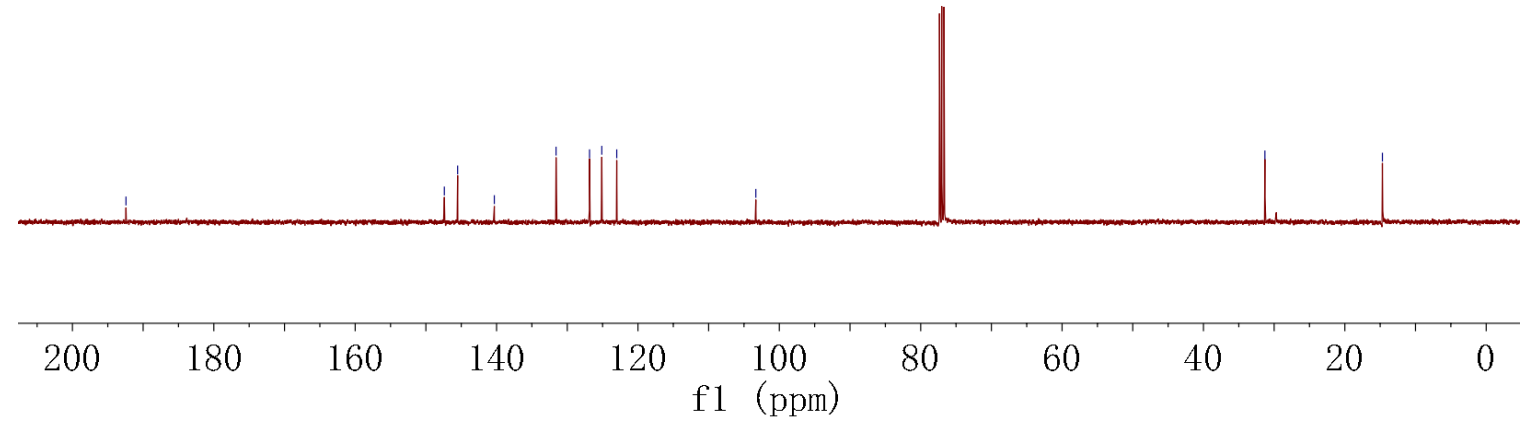


$7 \mathbf{x}$

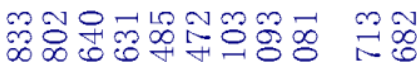

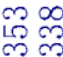

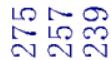

NNNNNNNN

लें

-<smiles>CCN=CC(=O)c1cccs1</smiles>

${ }^{1} \mathrm{H} \mathrm{NMR}\left(400 \mathrm{MHz}, \mathrm{CDCl}_{3}\right)$

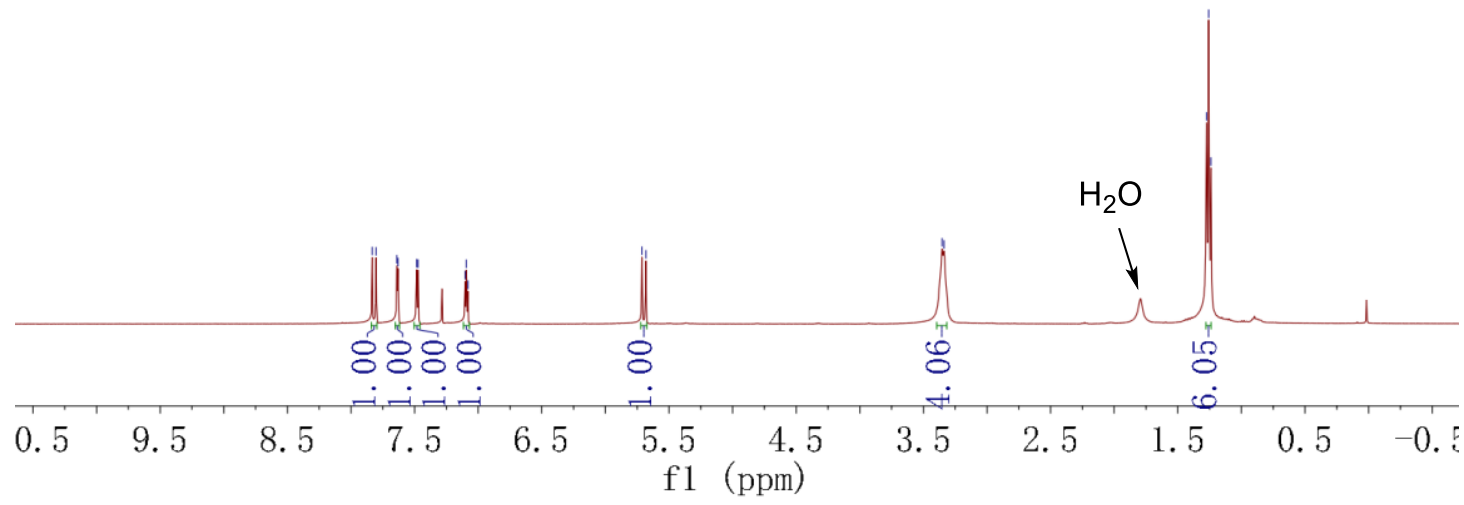

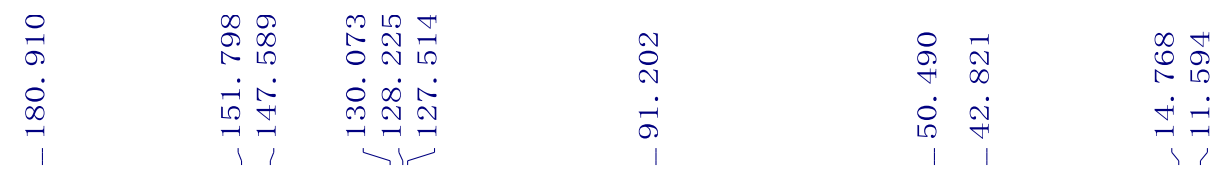

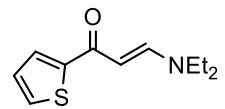

${ }^{13} \mathrm{C}\left\{{ }^{1} \mathrm{H}\right\}$ NMR $\left(101 \mathrm{MHz}, \mathrm{CDCl}_{3}\right)$

high boiling point impurities in petroleum ether

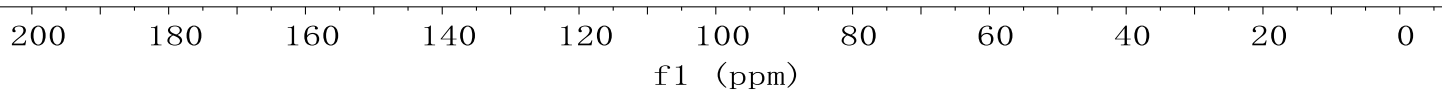


$7 z$

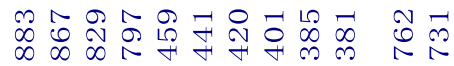

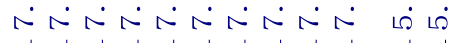

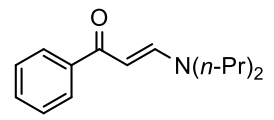

${ }^{1} \mathrm{H} \mathrm{NMR}\left(400 \mathrm{MHz}, \mathrm{CDCl}_{3}\right)$

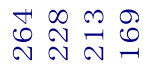

$\dot{\theta} \dot{\theta} \dot{\theta}$

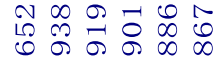

$-10000$

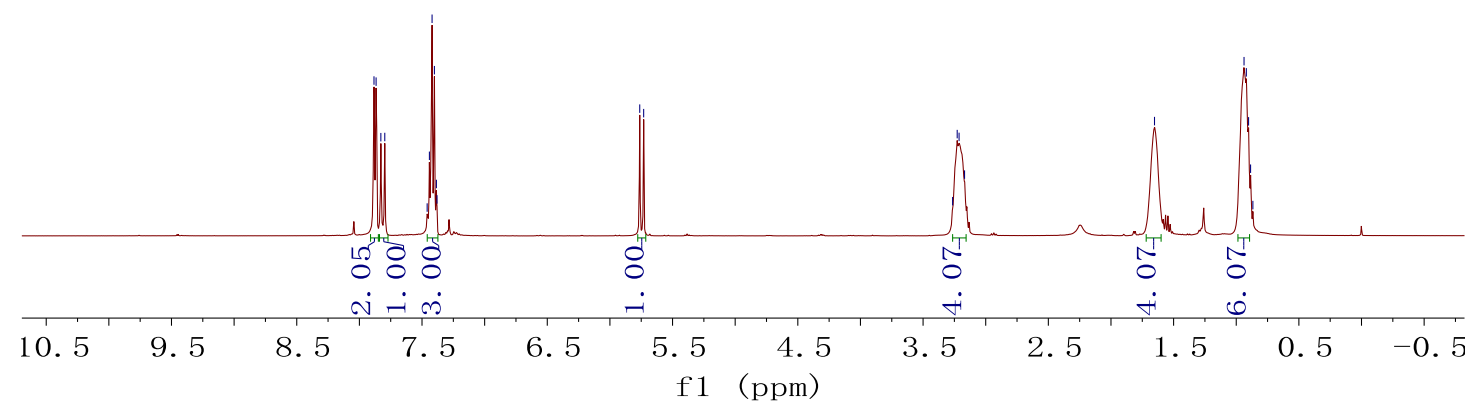

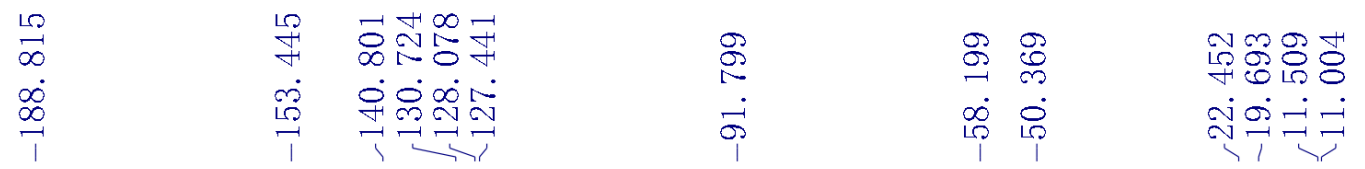<smiles>O=C(/C=C/N=Cc1ccccc1)c1ccccc1</smiles>

${ }^{13} \mathrm{C}\left\{{ }^{1} \mathrm{H}\right\}$ NMR $\left(101 \mathrm{MHz}, \mathrm{CDCl}_{3}\right)$

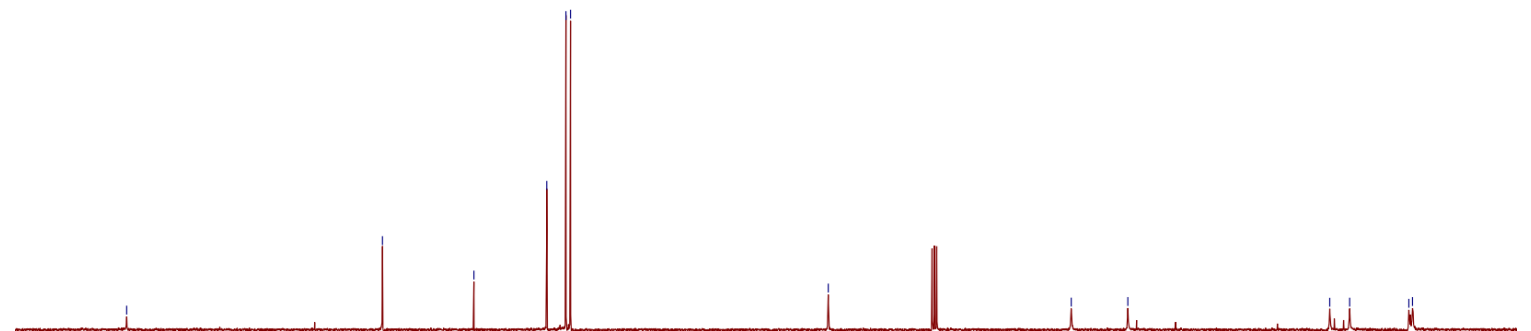


$7 a a$

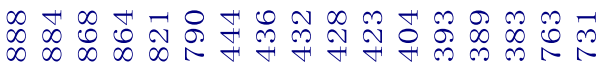

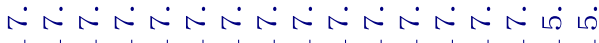

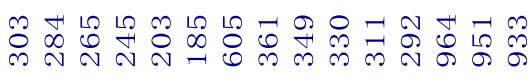

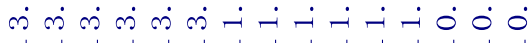<smiles>CCCCN(C=CC(=O)c1ccccc1)C(C)(C)C</smiles>

${ }^{1} \mathrm{H}$ NMR $\left(400 \mathrm{MHz}, \mathrm{CDCl}_{3}\right)$
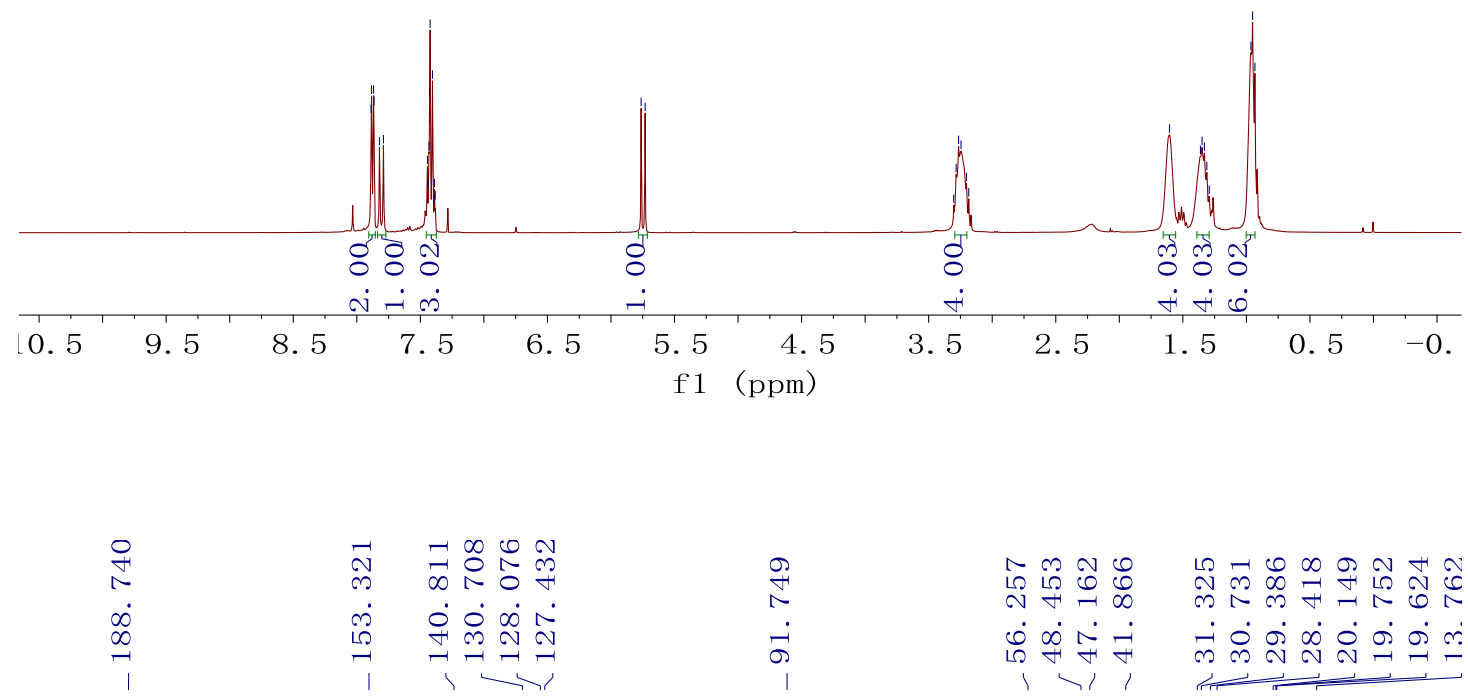<smiles>CCCCNC=CC(=O)c1ccccc1</smiles>

${ }^{13} \mathrm{C}\left\{{ }^{1} \mathrm{H}\right\}$ NMR $\left(101 \mathrm{MHz}, \mathrm{CDCl}_{3}\right)$
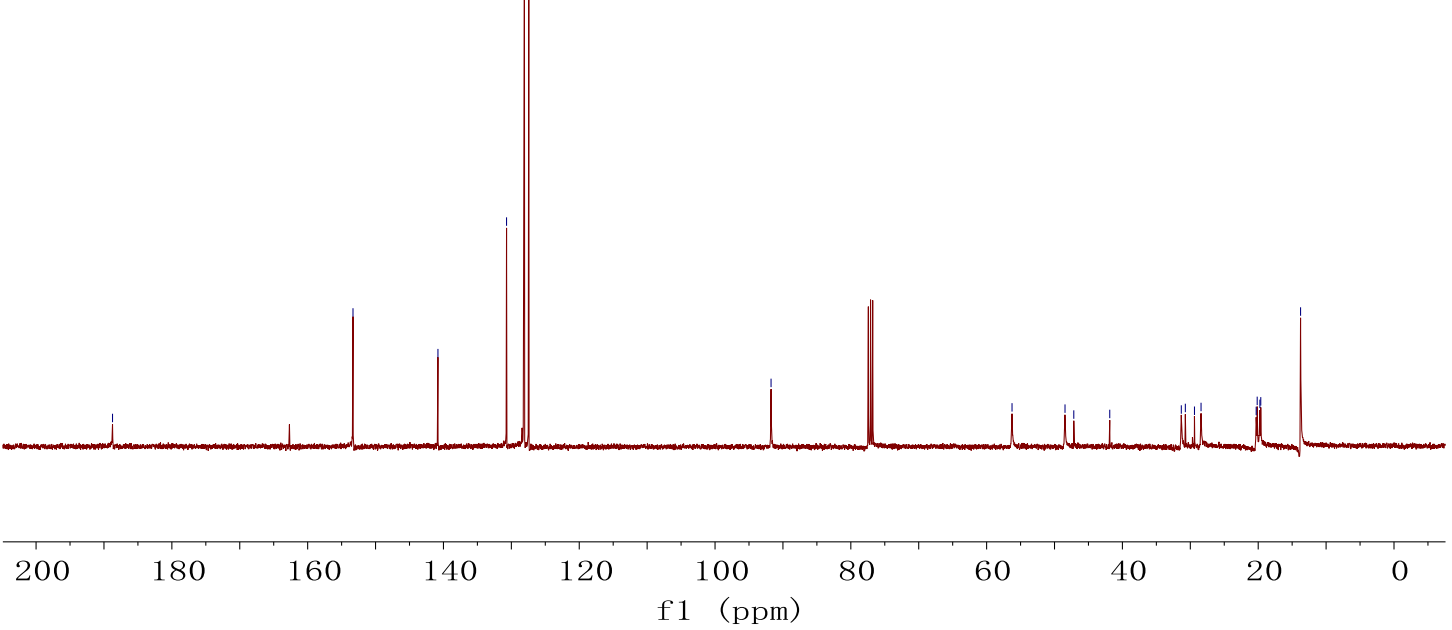
7ae'

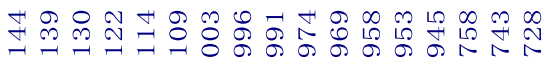

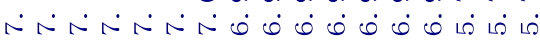

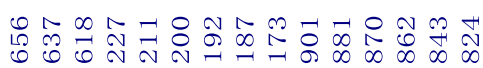

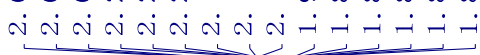<smiles>Fc1ccc(CCCCCl)cc1</smiles>

${ }^{1} \mathrm{H}$ NMR (400 MHz, $\mathrm{CDCl}_{3}$ )

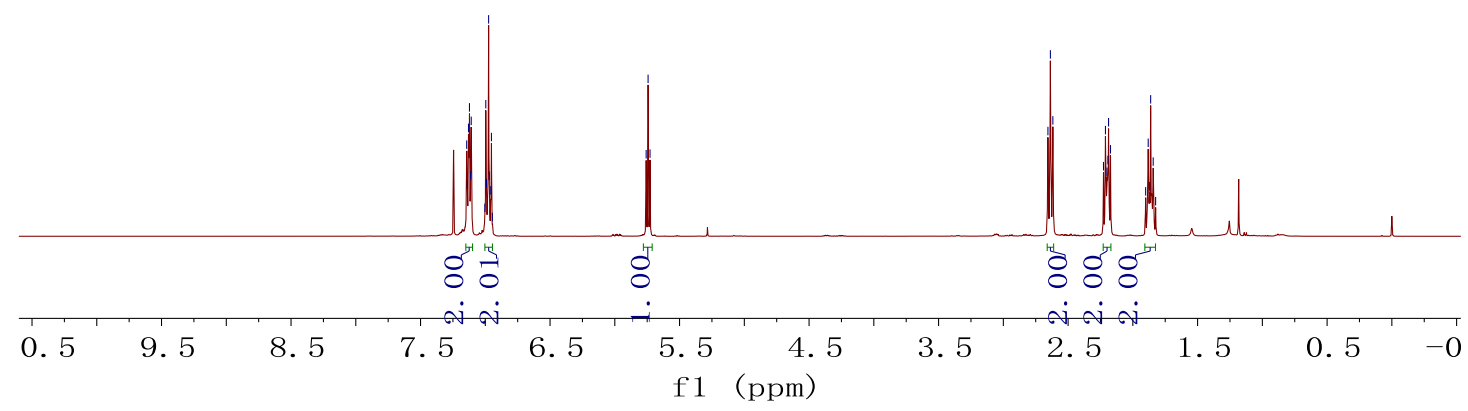

đֶ:

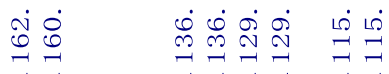

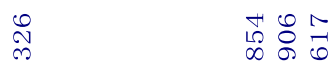

กี

$\mathrm{CHCl}_{2}$

${ }^{13} \mathrm{C}\left\{{ }^{1} \mathrm{H}\right\}$ NMR $\left(101 \mathrm{MHz}, \mathrm{CDCl}_{3}\right)$

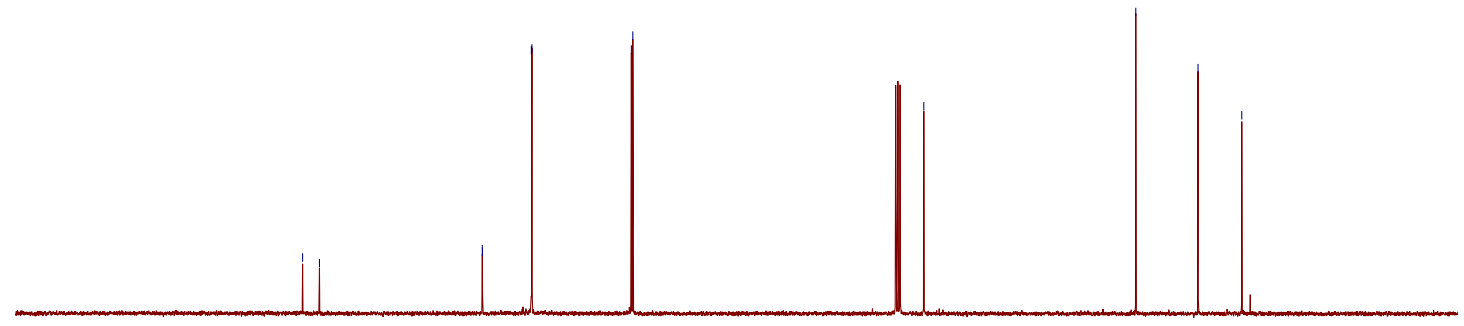

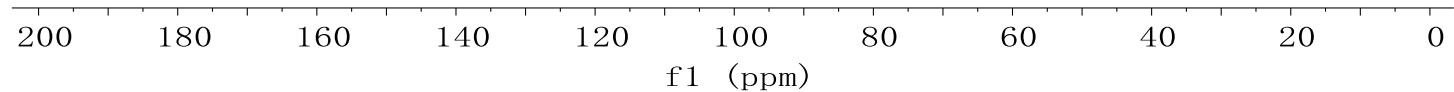


$8 a$

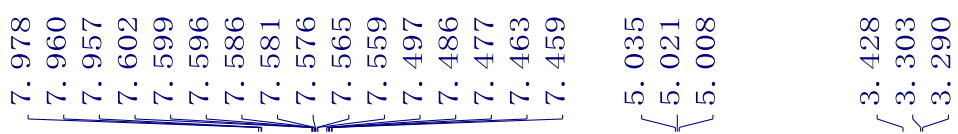

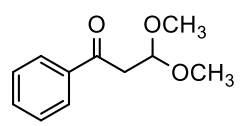

${ }^{1} \mathrm{H}$ NMR $\left(400 \mathrm{MHz}, \mathrm{CDCl}_{3}\right)$
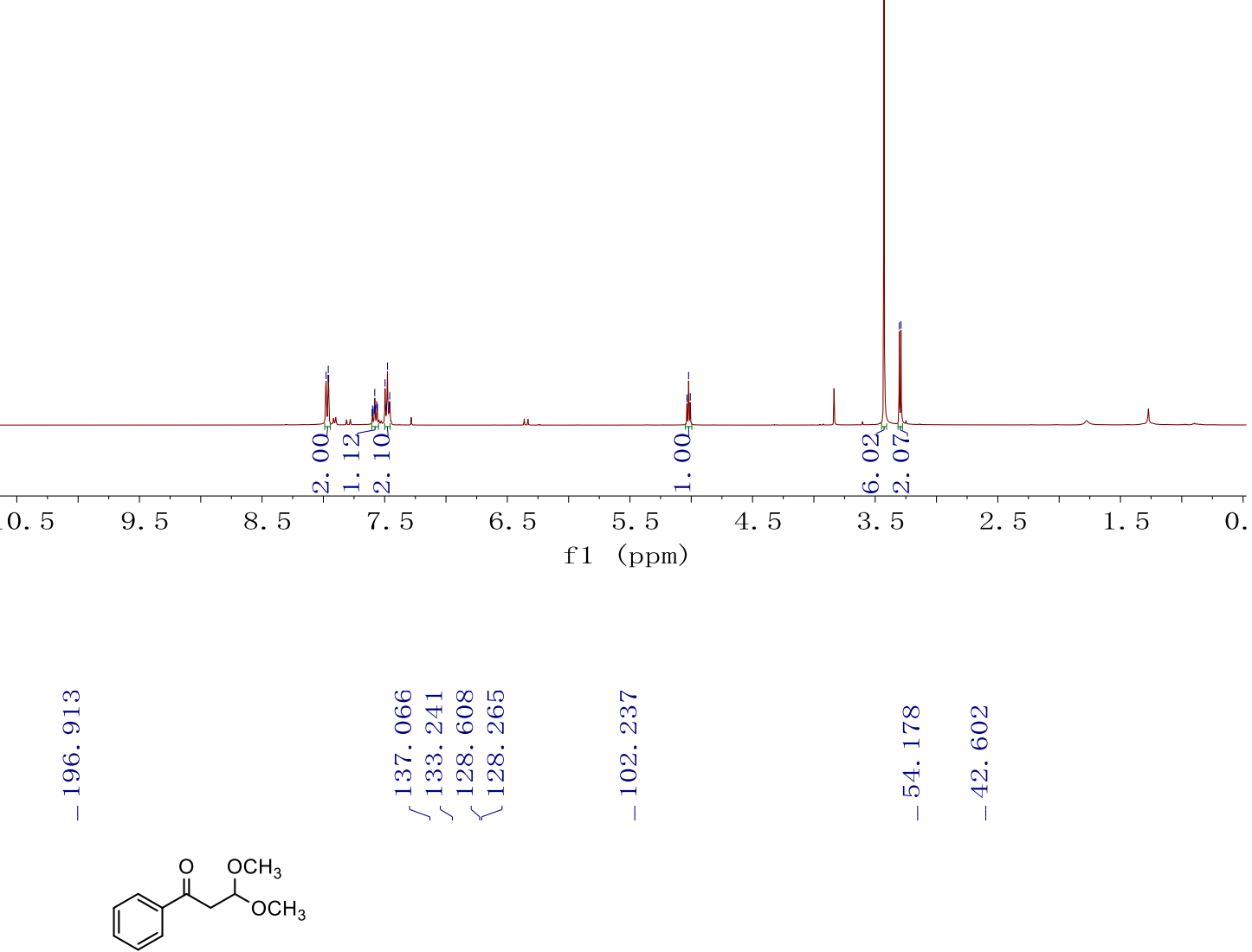

${ }^{13} \mathrm{C}\left\{{ }^{1} \mathrm{H}\right\}$ NMR (101 MHz, $\left.\mathrm{CDCl}_{3}\right)$
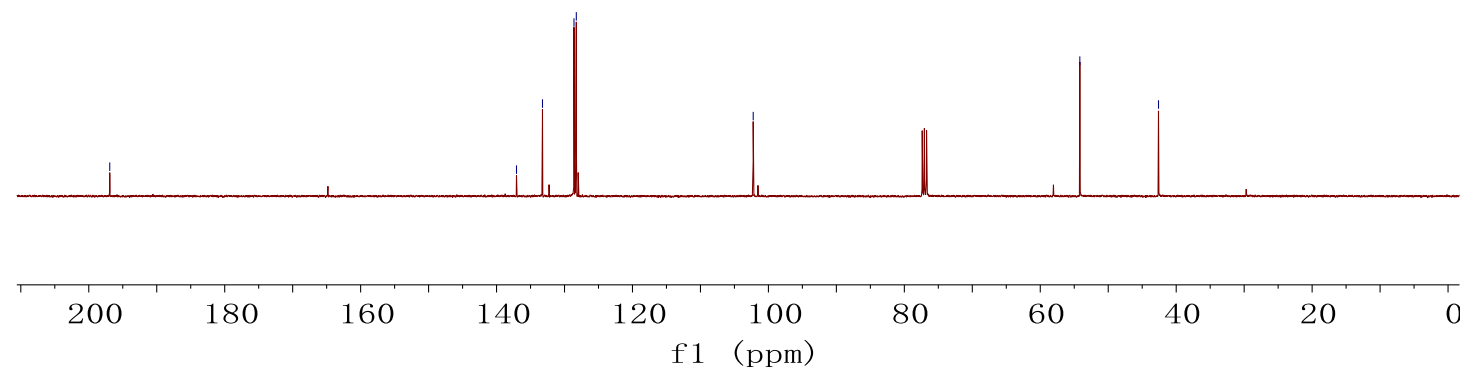


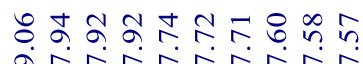

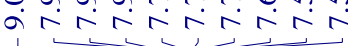

$\underbrace{O}_{S-N^{\prime \prime}}$

${ }^{1} \mathrm{H} \mathrm{NMR}\left(500 \mathrm{MHz}, \mathrm{CDCl}_{3}\right)$

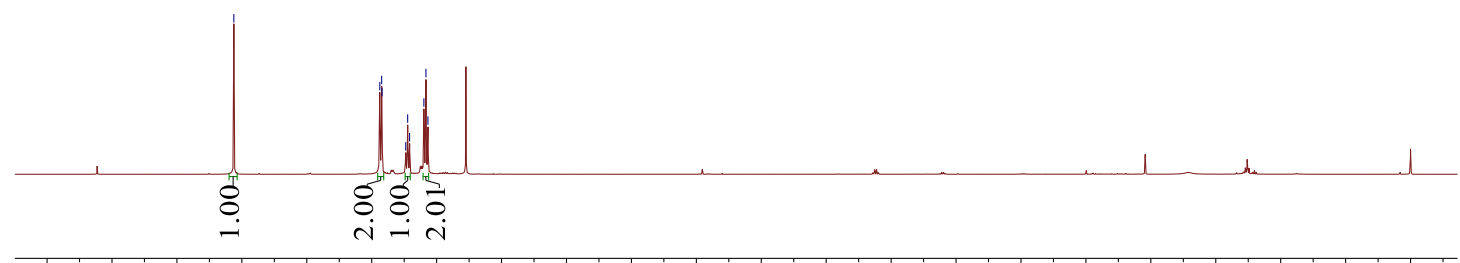

$\begin{array}{lllllllllllllllllllllllll}10.5 & 10.0 & 9.5 & 9.0 & 8.5 & 8.0 & 7.5 & 7.0 & 6.5 & 6.0 & 5.5 & 5.0 & 4.5 & 4.0 & 3.5 & 3.0 & 2.5 & 2.0 & 1.5 & 1.0 & 0.5 & 0.0\end{array}$

f1 (ppm)

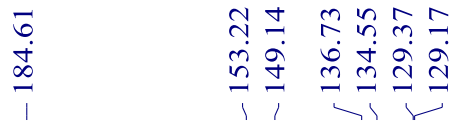<smiles>O=C(c1ccccc1)c1cnns1</smiles>

${ }^{13} \mathrm{C}\left\{{ }^{1} \mathrm{H}\right\}$ NMR $\left(126 \mathrm{MHz}, \mathrm{CDCl}_{3}\right)$

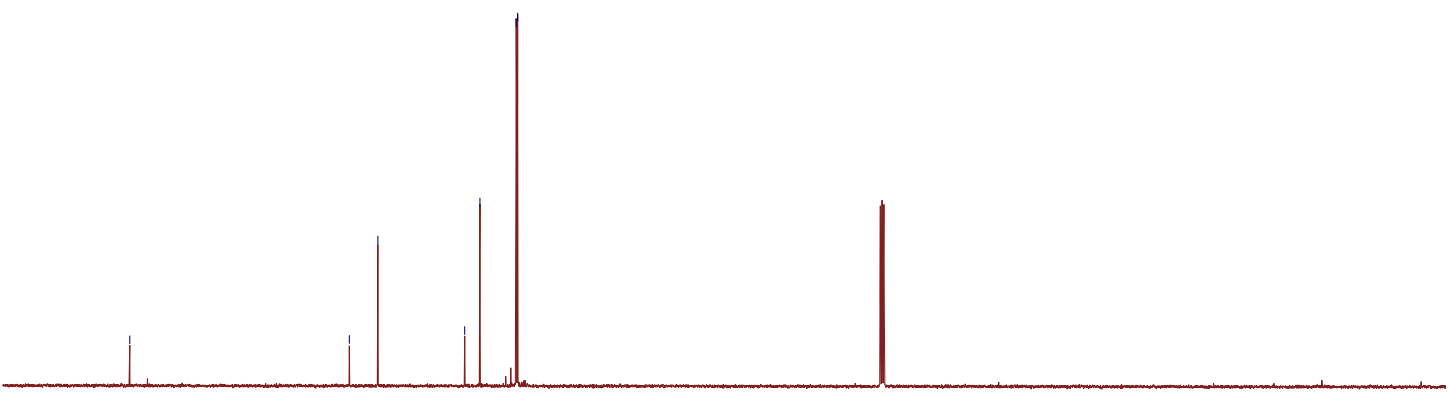

$\begin{array}{lllllllllllllllllllllllllllllll}1 & 190 & 190 & 180 & 170 & 160 & 150 & 140 & 130 & 120 & 110 & 100 & 90 & 80 & 70 & 60 & 50 & 40 & 30 & 20 & 10 & 0\end{array}$ 


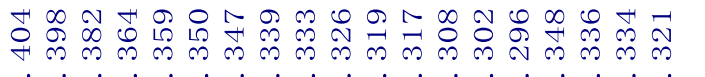

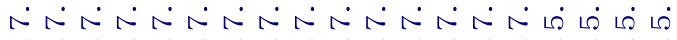

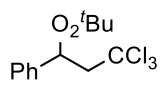

${ }^{1} \mathrm{H} \mathrm{NMR}\left(400 \mathrm{MHz}, \mathrm{CDCl}_{3}\right)$

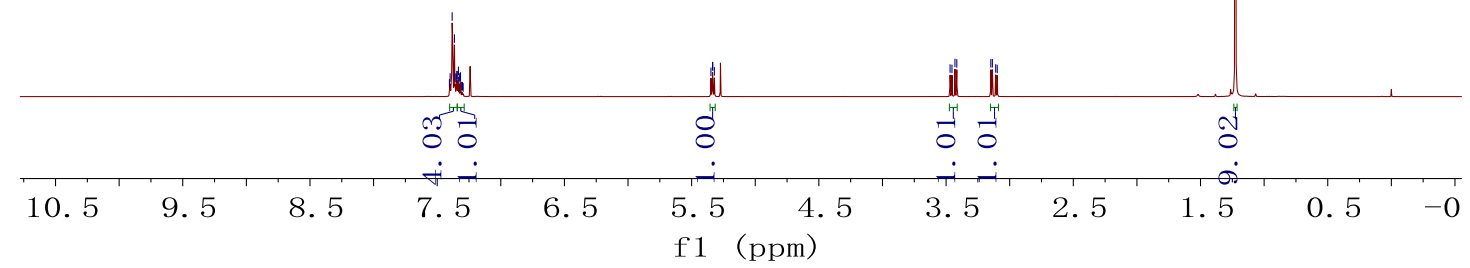

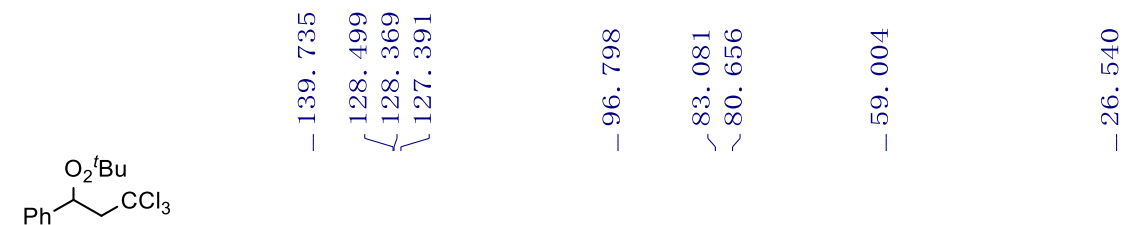

${ }^{13} \mathrm{C}\left\{{ }^{1} \mathrm{H}\right\} \mathrm{NMR}\left(101 \mathrm{MHz}, \mathrm{CDCl}_{3}\right)$

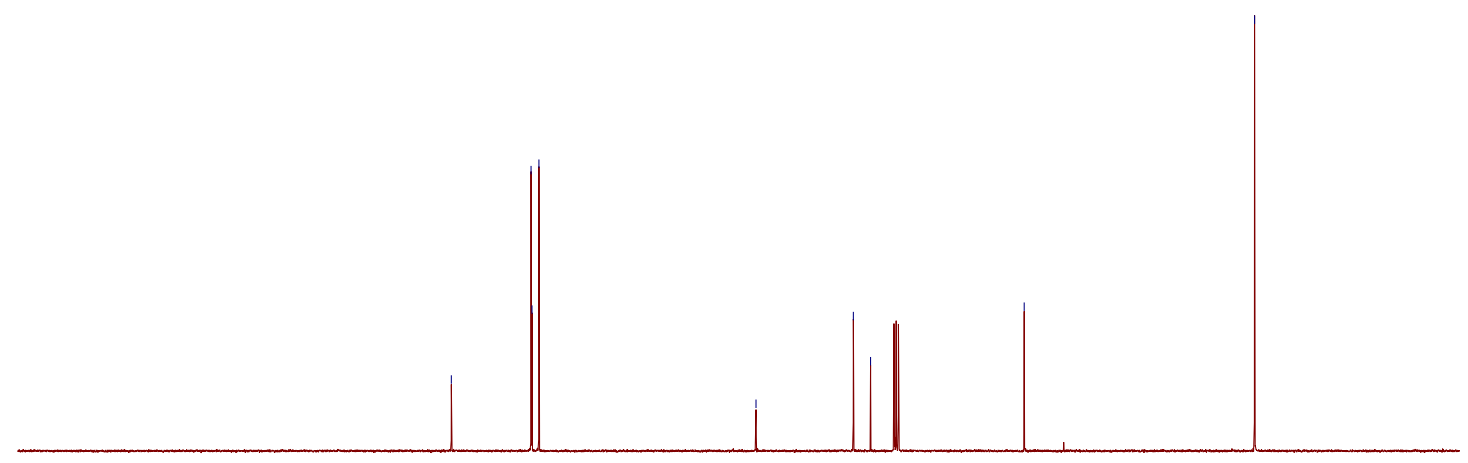

$00180 \quad 160 \quad 140 \quad 120 \begin{gathered}100 \\ f 1(\mathrm{ppm})\end{gathered}$

